\title{
Article \\ Towards High Efficacy of Pd-Au/C Catalyst for Tetrachloromethane Hydrodechlorination
}

\author{
Magdalena Bonarowska ${ }^{1, *}$, Zbigniew Kaszkur ${ }^{1}{ }^{\circledR}$, Krzysztof Matus $^{2} \odot$, Alicja Drelinkiewicz ${ }^{3}$, \\ Tomasz Szumełda ${ }^{3}$ and Adam Kubas ${ }^{1, *(D)}$ \\ 1 Polish Academy of Sciences, Kasprzaka 44/52, 01-224 Warsaw, Poland; zkaszkur@ichf.edu.pl \\ 2 Institute of Engineering Materials and Biomaterials, Silesian University of Technology, Konarskiego 18A, \\ 44-100 Gliwice, Poland; krzysztof.matus@polsl.pl \\ 3 Jerzy Haber Institute of Catalysis and Surface Chemistry, Polish Academy of Sciences, Niezapominajek 8, \\ 30-239 Krakow, Poland; ncdrelin@cyf-kr.edu.pl (A.D.); tomasz.szumelda@ncn.gov.pl (T.S.) \\ * Correspondence: mbonarowska@ichf.edu.pl (M.B.); akubas@ichf.edu.pl (A.K.); Tel.: +48-22-343-3356 (A.K.)
}

Citation: Bonarowska, M.; Kaszkur, Z.; Matus, K.; Drelinkiewicz, A.; Szumełda, T.; Kubas, A. Towards High Efficacy of Pd-Au/C Catalyst for Tetrachloromethane

Hydrodechlorination. Chemistry 2021, 3, 338-359. https://doi.org/10.3390/ chemistry3010025

Received: 26 January 2021

Accepted: 18 February 2021

Published: 1 March 2021

Publisher's Note: MDPI stays neutral with regard to jurisdictional claims in published maps and institutional affiliations.

Copyright: (c) 2021 by the authors. Licensee MDPI, Basel, Switzerland. This article is an open access article distributed under the terms and conditions of the Creative Commons Attribution (CC BY) license (https:/ / creativecommons.org/licenses/by/ $4.0 /)$.

\begin{abstract}
We present an efficient strategy for synthesising the PdAu catalysts with a homogeneous $\mathrm{PdAu}$ alloy phase for environmentally important hydrodechlorination of tetrachloromethane in the gas phase. The synthesis of carbon-supported catalysts involved two major steps: (i) incorporation of palladium and gold nanoparticles into carbon support and (ii) activation of the catalysts. The critical part of this work was to find the optimal conditions for both steps. Thus, the incorporation of the nanoparticles was carried out in two ways, by impregnation and direct redox reaction method using acetone solutions of metal precursor salts. The activation was performed either by a conventional thermal reduction in hydrogen or flash irradiation in a microwave oven. The homogeneity and structure of the PdAu alloy were found to depend on the catalyst activation method critically. In all cases, we observed better homogeneity for catalysts that were subject to microwave irradiation. Moreover, the flash microwave irradiation of prepared catalysts provided catalysts of better stability and selectivity towards the desired products (hydrocarbons) in the hydrodechlorination of tetrachloromethane as compared to the catalyst obtained by conventional thermal activation in hydrogen.
\end{abstract}

Keywords: hydrodechlorination; microwave irradiation; bimetallic catalysts; heterogeneous catalysis

\section{Introduction}

Tetrachloromethane $\left(\mathrm{CCl}_{4}\right)$ and many other chlorine-containing organic compounds are classified as hazardous gaseous waste due to their toxicity, carcinogenic nature, high global warming impact, and photochemical smog formation. The Montreal Protocol, 1987, and its subsequent updates have significantly reduced the emission of many organochlorine compounds into the atmosphere. Despite stringent limits on $\mathrm{CCl}_{4}$ production, use, and even transportation, global observations still indicate significant emissions of this pollutant to the atmosphere [1] and several industrial processes have been suggested as contributors to its persisting emission [2-4]. Therefore, methods for safe and environmentally acceptable destruction of recovered wastes or stocks of $\mathrm{CCl}_{4}$ are still needed.

From the economic and environmental point of view, catalytic hydrodechlorination $(\mathrm{HdCl})$, which operates at low temperatures and ambient pressures [5] is regarded as one of the most prospective methods of destruction of harmful chlorine-containing compounds.

The most desired products of hydrodechlorination of tetrachloromethane are dechlorinated hydrocarbons. However, removal of just one chlorine atom from the $\mathrm{CCl}_{4} \mathrm{molecule}$ yields chloroform $\left(\mathrm{CHCl}_{3}\right)$, which already has a lower environmental impact as compared to $\mathrm{CCl}_{4}$. Ozone Depletion Potential (ODP) and Global Warming Potential (GWP) for the both compounds are: $\mathrm{ODP}_{\mathrm{CCl} 4}=1.1, \mathrm{GWP}_{\mathrm{CCl} 4}=1730, \mathrm{ODP}_{\mathrm{CHCl} 3}=0.01, \mathrm{GWP}_{\mathrm{CHCl} 3}=16$ (for ODP and GWP values, the reference compound is from CFC-11, for which the values are 1.0 and 4600, respectively) [6]. 
Noble metals (Pd, $\mathrm{Pt}, \mathrm{Rh}, \mathrm{Au})$ and their alloys with non-noble metals are known for catalyzing hydrogenolysis of carbon-chlorine bonds, and they have become the most investigated elements for the removal of toxic chlorinated compounds [7-17]. Palladium was found to be unique for its activity in reactions of $\mathrm{HdCl}$. Consequently, most fundamental works were done with this metal [18-23]. However, the process of rapid catalyst deactivation by sintering and poisoning via coke formation is still a severe concern to Pd catalysts. Multiple element Pd-based alloys exhibit improved catalytic properties (such as selectivity to desired products, activity, resistance to poisoning, and metal sintering) compared to pure $\mathrm{Pd}$. Gold is considered to be inactive in $\mathrm{HdCl}$ reactions, but when mixed with $\mathrm{Pd}$, it creates a synergetic effect, resulting in significantly improved catalytic properties of $\mathrm{Pd}-\mathrm{Au}$ catalysts [5,24-27]. This synergism between $\mathrm{Au}$ and $\mathrm{Pd}$ nanoparticles includes electronic effect (electron transfer occurs between $\mathrm{Au}$ and $\mathrm{Pd}$, resulting in charge-heterogeneous active sites) and ensemble/geometric effect ( $\mathrm{Au}$, inactive in $\mathrm{HdCl}$ of $\mathrm{CCl}_{4}$, dilutes and isolates Pd sites) [28-30].

The size of the uniform metal particles and adequate homogeneity of the $\mathrm{Pd}-\mathrm{Au}$ alloy as an active metal phase are essential for improving the catalytic properties. However, the achievement of the structural homogeneity (in terms of the uniformity of the metal particle size and chemical composition), essential for most favorable catalytic properties, is still challenging. Our previous results show that very often, a satisfactory extent of $\mathrm{Pd}-\mathrm{Au}$ mixing was not achieved, especially for catalysts prepared by impregnation techniques [31,32]. More advanced preparation techniques, such as deposition of gold to palladium catalysts by redox reaction [27], give better results allowing a significantly higher, although still not perfect, degree of $\mathrm{Pd}-\mathrm{Au}$ alloying. Therefore, methods of improving the homogeneity of the metallic active phase are needed. It was found that the deposition of metal precursors on the support is strongly dependent on the impregnating medium and even a change in the solvent used during the preparation may have an impact on the homogeneity of the deposited metal particles [33]. The use of microwave radiation (MW) may improve the homogeneity of the active metallic phase of the catalyst. The advantage of the MW irradiation over conventional heating technologies are the speed and uniformity of heating. In a comprehensive review work [34] numerous examples of applications of microwave radiation are presented not only in many areas of the chemical industry, e.g., in chemical synthesis, hydrogen production, water purification (reduction of contaminants such as soot or NOx) but also in heterogeneous catalysis (including preparation of catalysts and catalytic reactions supported by this radiation). By virtue of uniform heating, MW irradiation has the potential to generate a more homogeneous bimetallic active phase both during and/or after the synthesis (post-synthetic treatment). Literature examples include improved homogeneity of $\mathrm{Pd}-\mathrm{Fe} / \mathrm{Al}_{2} \mathrm{O}_{3}$ [35], $\mathrm{Pt}-\mathrm{Ru} / \mathrm{CNT}$ [36] or $\mathrm{Ir}-\mathrm{Pt} / \mathrm{SiO}_{2}$ [37] catalysts. We also note that MW-assisted synthesis is a sustainable and environmentally friendly technique [38].

In this work, $\mathrm{Pd}, \mathrm{Au}$ and $\mathrm{Pd}-\mathrm{Au}$ catalysts supported on mesoporous, synthetic active carbon Sibunit were prepared. We compared the effect of MW irradiation and conventional thermal treatment in a hydrogen stream on the homogeneity of the metallic active phase of the catalysts and on the properties of these catalysts in the $\mathrm{HdCl}$ of $\mathrm{CCl}_{4}$. The catalysts' structures were characterized with several techniques (CO-chemisorption, XRD, XPS, TEM, mass spectrometry, palladium hydride phase decomposition and cyclic voltammetry). The structural features were correlated with the catalyst activity in the reaction of hydrodechlorination of tetrachloromethane $\left(\mathrm{HdCl}\right.$ of $\left.\mathrm{CCl}_{4}\right)$.

\section{Materials and Methods}

\subsection{Synthesis of Supported $P d, A u$, and $P d-A u$ Catalysts}

The synthetic carbon Sibunit [39] was used as the support for studied catalysts. Before using, the commercial Sibunit was washed with a boiling mixture of concentrated $\mathrm{HCl}$ and $\mathrm{HF}$, then purged with redistilled water and dried in an air oven at $373 \mathrm{~K}$ for $10 \mathrm{~h}$. 
Characteristics of carbon Sibunit after such a treatment procedure: powder with grain size $10-30 \mu \mathrm{m}$, BET surface area $271 \mathrm{~m}^{2} / \mathrm{g}$, BJH pore volume $0.31 \mathrm{~cm}^{3} / \mathrm{g}$, average pore diameter $57 \AA$.

Mono- and bimetallic $\mathrm{Pd}-\mathrm{Au}$ catalysts were prepared by the incipient wetness (co-) impregnation of Sibunit with appropriate amounts of acetone solutions of palladium(II)acetate (spectral purity, Ventron, Karlsruhe, Germany) and/or ammonium tetrachloroaurate(III) (spectral purity, Johnson Matthey, England). The details of impregnation procedures [40] have been described previously. The carbon-supported PdAu-DR catalyst was prepared via gold deposition using the direct redox method [41] onto previously synthesized monometallic $2.0 \mathrm{wt} \% \mathrm{Pd} / \mathrm{C}_{\text {Sibunit }}$ catalyst. All catalysts were prepared with constant loading of $2.64 \mathrm{wt} \%$ of metal component (sum of $\mathrm{Pd}+\mathrm{Au}$ ). In the bimetallic $\mathrm{Pd}-\mathrm{Au}$ catalysts, the molar ratio of $\mathrm{Pd}: \mathrm{Au}$ was 85:15. After preparation, preliminary drying in an air oven $\left(333 \mathrm{~K} / 5 \mathrm{~h}\right.$ ), drying in Ar flow at $373 \mathrm{~K}$ for $1 \mathrm{~h}$, and pre-reduction in a stream $20 \% \mathrm{H}_{2} / \mathrm{Ar}$ at $373 \mathrm{~K}$ for $0.5 \mathrm{~h}$, each catalyst sample was divided into two parts. The first part was activated using a conventional reduction in $20 \% \mathrm{H}_{2} / \mathrm{Ar}$ flow at $653 \mathrm{~K}$ for $3 \mathrm{~h}$ (catalysts marked in the text with the suffix $-653 \mathrm{~K}$ ). The second portion was activated by short-time microwave irradiation, $1050 \mathrm{~W}$ for $5 \mathrm{~s}$, in a microwave oven (Sharp R-941 INW, 2.45 GHz). The catalysts were irradiated in portions of $0.3 \mathrm{~g}$, in ceramic cuvettes situated on the oven plate always in the same place. These catalysts are termed as catalysts prepared by MW irradiation and marked with the suffix -MW. The pretreatments described above were applied both before the characterization measurements and before catalytic tests.

\subsection{Powder X-ray Diffraction (XRD)}

The XRD measurements of the catalysts after activation and catalysts after $\mathrm{HdCl}$ of $\mathrm{CCl}_{4}$ were done using D5000 diffractometer from Bruker AXS equipped with LynxEye strip detector (Billerica, MA, USA). They employed Ni-filtered $\mathrm{Cu} \mathrm{K} \alpha$ radiation (with an X-ray tube operating at $40 \mathrm{kV}$ and $40 \mathrm{~mA}$, and stability better than $0.01 \%$ for $8 \mathrm{~h}$ ) and Bragg-Brentano focusing geometry (with a beam divergence of $1^{\circ}$ in the scattering plane and $5^{\circ}$ divergence perpendicularly (Soller slits). The nanocrystallite XRD profiles were decomposed onto separate peaks (double Voigt profiles reflecting the use of the Ka1-Ka2 2:1 doublet) using Fityk program [42]. The decomposition followed the phase rule, i.e., a series of $f c c$ peaks had to correspond to roughly the same lattice parameter. The resulting integral peak widths (ratio of the peak area to its height) of the same crystal phase (usually three peaks) were analyzed for a possible effect of microstrain to arrive at the most appropriate crystal size (listed in Table 1). The peak positions were corrected for typical diffractometer errors (like sample effective surface displacement) by relating it to a 002 carbon peak position considered as not affected by the sample synthesis and treatment.

\subsection{CO-Chemisorption}

The chemisorption experiments were performed in a static system, using a double isotherm method (ASAP 2020C instrument from Micromeritics; Norcross, GE, USA) at $308 \mathrm{~K}$ in pressures ranging from $1 \mathrm{mTorr}$ to 900 Torr. The metal dispersion was determined using the total chemisorption isotherms and assuming CO:M stoichiometries of 1.5:1 (where $\mathrm{M}=\mathrm{Pd}+\mathrm{Au})$.

\subsection{Transmission Electron Microscopy (TEM)}

The TEM measurements were performed on a Cs-corrected S/TEM Titan 80-300 FEI microscope with an EDAX EDS detector (FEI Company, Hillsboro, OR, USA). The samples were studied using STEM-mode with the high-angle annular dark-field (HAADF) and an electron beam with a convergence semi-angle of $24 \mathrm{mrad}$ at $300 \mathrm{keV}$. A HAADF detector was used to collect electrons at a large angle due to elastic scattering; the contrast in obtained images is proportional to the square of the electric charge of the nucleus $(\mathrm{I}(\mathrm{X}) \sim \mathrm{Z2})$. The sample preparation involved dispersion of the samples in ethanol, solution sonication, 
deposition on copper grids coated with a film of amorphous carbon and drying in air at room temperature.

\subsection{Temperature-Programmed $\beta$-Hydride Phase Decomposition (TPHD)}

The TPHD experiments were performed in a flow system, equipped with a GOWMAC thermal conductivity detector, using a $10 \% \mathrm{H}_{2}$ in Ar gas mixture at a flow rate of $25 \mathrm{~cm}^{3} / \mathrm{min}$ and a heating rate of $8 \mathrm{~K} / \mathrm{min}$ in the temperature range 273-473 K. Such experiments aimed to monitor hydrogen evolution in the process of $\beta$-hydride phase decomposition [43].

\subsection{The Cyclic Voltammetry (CV)}

The CV measurements were carried out in a conventional three-electrode electrochemical cell using a CH Instrument (Austin, TX, USA) Model 760D workstation. A graphite rod and a mercury / mercury sulfate electrode $\left(\mathrm{Hg} / \mathrm{Hg}_{2} \mathrm{SO}_{4}, 0.718 \mathrm{~V}\right.$ vs. reversible hydrogen electrode), were used as the counter electrode and the reference electrode, respectively. A glassy carbon disk electrode (GC) $\left(2.805 \mathrm{~mm}\right.$ radius, geometric area, $\left.0.247 \mathrm{~cm}^{2}\right)$ was used as the working electrode. The ink of carbon-supported catalysts was prepared by ultrasonically mixing $5 \mathrm{mg}$ of catalyst sample with $0.029 \mathrm{~cm}^{3}$ of Nafion $(5 \mathrm{wt} . \%$ in lower aliphatic alcohols and water, Aldrich) in $1 \mathrm{~cm}^{3}$ of 2-propanol solution. $13.3 \mu \mathrm{L}$ of the suspension was dropped onto the GC electrode by a microsyringe and left to dry (ca. $30 \mathrm{~min}$ ) at room temperature (corresponds to constant Pd loading on the electrode $10 \mu \mathrm{g} / \mathrm{cm}^{2}$ ). All electrochemical experiments were performed in an Ar deoxygenated solution at a scan rate of $50 \mathrm{mV} / \mathrm{s}$ at room temperature and ambient pressure, employing $0.5 \mathrm{M}$ sulfuric acid as the electrolyte solution. The potentials values given in the text are referred to the reversible hydrogen electrode (RHE).

\subsection{Catalytic Tests-Hydrodechlorination of Tetrachloromethane ( $\mathrm{HdCl}$ of $\mathrm{CCl}_{4}$ )}

The reactions were carried out at $363 \mathrm{~K}$ and the $\mathrm{H}_{2}$-to- $\mathrm{CCl}_{4}$ ratio of 14:1, in a glass flow system, as previously described [44]. Partial pressures of the reaction mixture were: $\mathrm{CCl}_{4} 4.3 \mathrm{kPa}, \mathrm{H}_{2} 60.5 \mathrm{kPa}$, Ar $36.5 \mathrm{kPa}$. $\mathrm{CCl}_{4}$ was provided from a saturator maintained at $273 \mathrm{~K}( \pm 0.1 \mathrm{~K})$ and bubbled in a flow of $\mathrm{H}_{2} / \mathrm{Ar}$ mixture $\left(29 \mathrm{~cm}^{3} / \mathrm{min}\right)$. The flows of $\mathrm{H}_{2}$ and Ar (both $99.999 \%$ pure) were fixed with mass flow controllers. In all cases, $0.2 \mathrm{~g}$ of each catalyst was used. The reaction was carried out at $363 \mathrm{~K}$ and a typical run lasted for $\sim 22 \mathrm{~h}$. Blank kinetic experiments with carbon support showed low conversions, $<0.01 \%$. The catalytic performances were followed by gas chromatography (HP 5890 series II with FID, 5\% Fluorcol/Carbopack B column (10 ft) from Supelco). The use of small catalyst grains, 10-30 $\mu \mathrm{m}$, significantly reduced internal diffusion. The effect of external diffusion was checked for the PdAu-DR-MW catalyst, which exhibited a final conversion level of $\sim 45 \%$. In order to maintain a constant contact time, the reaction was additionally carried out using half of the standard catalyst mass (i.e., $0.1 \mathrm{~g}$ ) and reactant flow reduced by half. The experiments showed reasonably good agreement in the conversion values ( $42 \%$ for the lower gas flow) and product distribution for both conditions, suggesting that the external transport does not affect $\mathrm{HdCl}$ performance under the applied conditions. The reproducibility of results (checked on samples of PdAu-DR-653 K and PdAu-DR-MW catalysts) was satisfactory-activity and selectivity towards desired products were $\sim 2-4 \%$.

\subsection{Temperature-Programmed Hydrogenation of Catalysts after $\mathrm{HdCl}$ of $\mathrm{CCl}_{4}$ (TPH-MS)}

The TPH-MS experiments were carried out in a flow of $20 \% \mathrm{H}_{2}-80 \% \mathrm{He}$ mixture $\left(25 \mathrm{~cm}^{3} / \mathrm{min}\right.$ ) and a heating ramp of $10 \mathrm{~K} / \mathrm{min}$ from $\mathrm{RT}$ to $1050 \mathrm{~K}$. The evolved gases were followed by mass spectrometry (MA200, Dycor-Ametek, Pittsburgh, PE, USA). The attention was mainly paid to the $\mathrm{m} / z 16$ (methane evolution) and $\mathrm{m} / z 36$ ( $\mathrm{HCl}$ liberation). 


\section{Results and Discussion}

\subsection{Characterisation of $P d-A u / S i b u n i t$ Catalysts}

Table 1 lists the catalysts used in this study, their composition, and morphological characterization.

Table 1. Pd, Pd-Au and $\mathrm{Au} / \mathrm{C}_{\text {Sibunit }}$ catalysts, their composition and physicochemical characterization.

\begin{tabular}{|c|c|c|c|c|c|c|c|}
\hline \multirow{2}{*}{$\begin{array}{c}\text { Catalyst } \\
\text { Designation } 1,2\end{array}$} & \multirow{2}{*}{$\begin{array}{c}\text { Catalyst Composition }{ }^{3} \text { and } \\
\text { Activation Method }\end{array}$} & \multicolumn{2}{|c|}{ CO Chemisorption $^{4}$} & \multicolumn{2}{|c|}{ TPHD $^{5}$} & \multirow{2}{*}{$\begin{array}{l}\text { XRD Analysis (Metal } \\
\text { Dominant Phases) }\end{array}$} & \multirow{2}{*}{ TEM } \\
\hline & & $\mathrm{FE}^{6}$ & $\mathrm{~d}, \mathrm{~nm}$ & $\mathrm{H} / \mathrm{Pd}^{6}$ & $\mathrm{~T}_{\max }, \mathrm{K}$ & & \\
\hline Pd-IMP-653 K & $\begin{array}{c}2.64 \mathrm{wt} \% \mathrm{Pd} / \mathrm{C}_{\text {sib }} \\
\text { reduction in } \mathrm{H}_{2} / 653 \mathrm{~K} / 3 \mathrm{~h}\end{array}$ & 0.40 & 2.8 & 0.18 & 349.0 & $\mathrm{Pd} 2.2 \mathrm{~nm}$ & not tested \\
\hline Pd-IMP-MW & $\begin{array}{c}2.64 \mathrm{wt} \% \mathrm{Pd} / \mathrm{C}_{\text {sib }} \\
\mathrm{MW} \text { irradiation } / 1050 \mathrm{~W} / 5 \mathrm{~s}\end{array}$ & 0.21 & 5.3 & 0.41 & 354.4 & $\mathrm{Pd} 4.4 \mathrm{~nm}$ & \\
\hline PdAu-IMP-653 K & $\begin{array}{l}2.64 \mathrm{wt} \% \mathrm{Pd}_{85} \mathrm{Au}_{15} / \mathrm{C}_{\text {sib }} \\
\text { reduction in } \mathrm{H}_{2} / 653 \mathrm{~K} / 3 \mathrm{~h}\end{array}$ & 0.23 & 5.2 & 0.14 & 350.2 & $\begin{array}{c}\mathrm{Pd} 2.3 \mathrm{~nm} \\
\mathrm{Pd}_{42} \mathrm{Au}_{58} 4.0 \mathrm{~nm} \\
\operatorname{Pd}_{13} \mathrm{Au}_{87} 3.4 \mathrm{~nm}\end{array}$ & $\begin{array}{c}\mathrm{d}_{\mathrm{avg}}=2.6 \mathrm{~nm} \\
1.3-4.9 \mathrm{~nm}\end{array}$ \\
\hline PdAu-IMP-MW & $\begin{array}{c}2.64 \mathrm{wt} \% \mathrm{Pd}_{85} \mathrm{Au}_{15} / \mathrm{C}_{\text {sib }} \\
\mathrm{MW} \text { irradiation } / 1050 \mathrm{~W} / 5 \mathrm{~s}\end{array}$ & 0.12 & 9.5 & 0.20 & 354.8 & $\begin{array}{l}\mathrm{Pd}_{72} \mathrm{Au}_{28} 6.3 \mathrm{~nm} \\
\mathrm{Pd}_{25} \mathrm{Au}_{75} 3.7 \mathrm{~nm}\end{array}$ & $\begin{array}{c}\mathrm{d}_{\mathrm{avg}}=3.9 \mathrm{~nm} \\
2.1-5.3 \mathrm{~nm}\end{array}$ \\
\hline PdAu-DR-653 K & $\begin{array}{l}2.64 \mathrm{wt} \% \mathrm{Pd}_{85} \mathrm{Au}_{15} / \mathrm{C}_{\text {sib }} \\
\text { reduction in } \mathrm{H}_{2} / 653 \mathrm{~K} / 3 \mathrm{~h}\end{array}$ & 0.13 & 8.7 & 0.23 & 353.6 & $\begin{array}{c}\mathrm{Pd} 4.1 \mathrm{~nm} \\
\mathrm{Pd}_{37} \mathrm{Au}_{63} 6.4 \mathrm{~nm} \\
\mathrm{Pd}_{89} \mathrm{Au}_{11} 5.8 \mathrm{~nm}\end{array}$ & $\begin{array}{c}\mathrm{d}_{\mathrm{avg}}=3.8 \mathrm{~nm} \\
1.8-7.9 \mathrm{~nm}\end{array}$ \\
\hline PdAu-DR-MW & $\begin{array}{c}2.64 \mathrm{wt} \% \mathrm{Pd}_{85} \mathrm{Au}_{15} / \mathrm{C}_{\text {sib }} \\
\mathrm{MW} \text { irradiation } / 1050 \mathrm{~W} / 5 \mathrm{~s}\end{array}$ & 0.09 & 12.3 & 0.28 & 355.9 & $\begin{array}{l}\mathrm{Pd}_{77} \mathrm{Au}_{23} 6.2 \mathrm{~nm} \\
\mathrm{Pd}_{26} \mathrm{Au}_{74} 6.6 \mathrm{~nm}\end{array}$ & $\begin{array}{c}\mathrm{d}_{\mathrm{avg}}=5.1 \mathrm{~nm} \\
2.2-7.0 \mathrm{~nm}\end{array}$ \\
\hline Au-IMP-653 K & $\begin{array}{c}2.64 \mathrm{wt} \% \mathrm{Au} / \mathrm{C}_{\text {sib }} \\
\text { reduction in } \mathrm{H}_{2} / 653 \mathrm{~K} / 3 \mathrm{~h}\end{array}$ & \multicolumn{2}{|c|}{ no $\mathrm{CO}$ chemisorption } & \multicolumn{2}{|c|}{ no $\mathrm{H}_{2}$ release } & $\mathrm{Au} 15.0 \mathrm{~nm}$ & not tested \\
\hline Au-IMP-MW & $\begin{array}{c}2.64 \mathrm{wt} \% \mathrm{Au} / \mathrm{C}_{\mathrm{sib}} \\
\text { MW irradiation } / 1050 \mathrm{~W} / 5 \mathrm{~s}\end{array}$ & \multicolumn{2}{|c|}{ as above } & \multicolumn{2}{|c|}{ as above } & $\mathrm{Au} 17.0 \mathrm{~nm}$ & \\
\hline
\end{tabular}

${ }^{1}$ Acronyms IMP and DR denote preparation method of the catalyst, e.g., incipient wetness impregnation and direct redox method, respectively. ${ }^{2}$ In catalyst designation: the suffix $-653 \mathrm{~K}$ denotes catalysts activated by reduction in $20 \% \mathrm{H}_{2} / \mathrm{Ar}$ flow at $653 \mathrm{~K}$; the suffix-MW catalysts activated by microwave irradiation. ${ }^{3}$ In catalyst composition designation, 2.64 denotes the total metal wt. $\%$, and subscripts (for $\mathrm{PdAu}$ catalysts) denote atom percentages of $\mathrm{Pd}$ and $\mathrm{Au}$ in the metal phase. ${ }^{4}$ Adsorption stoichiometry $\mathrm{CO}_{\mathrm{ads}} /(\mathrm{Pd}+\mathrm{Au})$ $=1.5 .{ }^{5} \mathrm{In}$ subcolumn $\mathrm{FE}$, the metal fraction exposed $\left[\mathrm{CO}_{\mathrm{ads}} /(\mathrm{Pd}+\mathrm{Au})\right]$ and $\mathrm{d}$ (metal particle size) are calculated as 1.2/FE $[45] .{ }^{6} \mathrm{In}$ subcolumn $\mathrm{H} / \mathrm{Pd}$ is shown the ratio of moles of $\mathrm{H}_{2}$ released during TPHD trace to moles of $\mathrm{Pd}, \mathrm{T}_{\max }$ shows the position of maximum in the trace.

Earlier studies $[33,46,47]$ showed that the deposition of metal precursors on a catalyst support is strongly dependent on the support properties, the metal salt solvent used and the preparation method. In contrast to our previous work [48], the current catalysts were prepared from acetone solutions of metal precursor salts instead of aqueous ones. The change in the solvent significantly improved the uniformity of the active metallic phase, i.e., narrower distributions of the size of metal nanoparticles and better homogeneity of bimetallic systems were obtained using acetone solutions. Table 2 shows examples of differences in the final phase composition and size of crystallites for $\mathrm{Pd}-\mathrm{Au}$ bimetallic catalysts (nominal composition $2.64 \mathrm{wt} \% \mathrm{Pd}_{85} \mathrm{Au}_{15} / \mathrm{C}$ ), which were prepared from aqueous solutions metal precursor salts (our previous work [48]) and acetone solutions (current work).

We speculate that using an organic solvent favors a more uniform distribution of the $\mathrm{Pd}$ and Au precursors in a hydrophobic pore structure of the carbon material. It seems that a limited wetting of the carbon material by aqueous medium results in the deposition of more massive clusters of metal precursors and, in effect, leads to the preparation of low metal dispersed catalysts and inhomogeneous particle size distribution. 
Table 2. Effect of metal precursor salts solvent on metal phase composition-illustrative results from XRD analysis for differently prepared and activated $2.64 \mathrm{wt} \% \mathrm{Pd}_{85} \mathrm{Au}_{15} / \mathrm{C}$ catalysts.

\begin{tabular}{|c|c|c|c|c|}
\hline \multirow{2}{*}{$\begin{array}{c}\text { Method of } \\
\text { Preparation and } \\
\text { Activation Method }\end{array}$} & \multicolumn{2}{|c|}{ Prepared from Aqueous Solutions [48] } & \multicolumn{2}{|c|}{ Prepared from Acetone Solutions (Current Work) } \\
\hline & $\begin{array}{c}\text { Dominant Metal } \\
\text { Phases }\end{array}$ & $\begin{array}{c}\text { Size of Crystallites, } \\
\mathrm{nm}\end{array}$ & Dominant Metal Phases & $\begin{array}{c}\text { Size of Crystallites, } \\
\mathrm{nm}\end{array}$ \\
\hline \multirow{3}{*}{$\begin{array}{l}\text { Coimpregnation } \\
\mathrm{H}_{2}, 653 \mathrm{~K}, 3 \mathrm{~h}\end{array}$} & $\mathrm{Pd}$ & 4.5 & $\mathrm{Pd}$ & 2.3 \\
\hline & $\mathrm{Pd}_{30} \mathrm{Au}_{70}$ & 2.0 & $\mathrm{Pd}_{42} \mathrm{Au}_{58}$ & 4.0 \\
\hline & $\mathrm{Au}$ & 35.0 & $\mathrm{Pd}_{13} \mathrm{Au}_{87}$ & 3.4 \\
\hline \multirow{2}{*}{$\begin{array}{l}\text { Coimpregnation } \\
\text { MW, } 1050 \mathrm{~W}, 5 \mathrm{~s}\end{array}$} & $\mathrm{Pd}$ & 3.6 & \multirow{2}{*}{$\begin{array}{l}\mathrm{Pd}_{72} \mathrm{Au}_{28} \\
\mathrm{Pd}_{25} \mathrm{Au}_{75}\end{array}$} & \multirow{2}{*}{$\begin{array}{l}6.3 \\
3.7\end{array}$} \\
\hline & $\begin{array}{c}\mathrm{Pd}_{30} \mathrm{Au}_{70} \\
\mathrm{Au}\end{array}$ & $\begin{array}{c}9.0 \\
29.0\end{array}$ & & \\
\hline \multirow{3}{*}{$\begin{array}{l}\text { direct redox method } \\
\qquad \mathrm{H}_{2}, 653 \mathrm{~K}, 3 \mathrm{~h}\end{array}$} & $\mathrm{Pd}_{28} \mathrm{Au}_{72}$ & 6.4 & \multirow{3}{*}{$\begin{array}{c}\mathrm{Pd} \\
\mathrm{Pd}_{37} \mathrm{Au}_{63} \\
\mathrm{Pd}_{89} \mathrm{Au}_{11}\end{array}$} & 4.1 \\
\hline & $\mathrm{Pd}_{83} \mathrm{Au}_{17}$ & 3.0 & & 6.4 \\
\hline & $\mathrm{Pd}_{94} \mathrm{Au}_{6}$ & 13.7 & & 5.8 \\
\hline \multirow{3}{*}{$\begin{array}{l}\text { direct redox method } \\
\mathrm{MW}, 1050 \mathrm{~W}, 5 \mathrm{~s}\end{array}$} & $\mathrm{Pd}_{37} \mathrm{Au}_{63}$ & 7.3 & \multirow{3}{*}{$\begin{array}{l}\mathrm{Pd}_{77} \mathrm{Au}_{23} \\
\mathrm{Pd}_{26} \mathrm{Au}_{74}\end{array}$} & \multirow{3}{*}{$\begin{array}{l}6.2 \\
6.6\end{array}$} \\
\hline & $\mathrm{Pd}_{75} \mathrm{Au}_{25}$ & 3.4 & & \\
\hline & $\mathrm{Pd}$ & 11.0 & & \\
\hline
\end{tabular}

MW irradiation often improves the homogeneity of metal particles deposited on the support [34]. To find optimal conditions for this step, we checked several combinations of irradiation power and time: catalyst $\mathrm{PdAu}-\mathrm{DR}$, after drying and pre-reduction in $20 \% \mathrm{H}_{2}$ Ar flow $/ 373 \mathrm{~K} / 0.5 \mathrm{~h}$, was irradiated under different conditions including the irradiation power (315-1050 W) and time (5-90 s). As the optimum flash, 5-s, irradiation time at $1050 \mathrm{~W}$ were chosen. For such conditions, the best mixing of palladium and gold was found, while the size of the PdAu particles did not increase too much relative to that of the initial one. Using less than the maximum power of $1050 \mathrm{~W}$ resulted in more insufficient mixing of the two metals, while increasing the irradiation time increased the metal particle size without affecting the homogeneity quality of the $\mathrm{Pd}-\mathrm{Au}$ alloy.

Figure 1 shows XRD profiles in the vicinity of the (111) reflection for all tested catalysts (the positions of (111) reflections of $f c c$ phases of $\mathrm{Pd}$ and $\mathrm{Au}$ are marked). XRD profiles provide crucial information on the composition of the synthesized $\mathrm{PdAu} / \mathrm{C}$ catalysts. The application of MW irradiation for activation gives larger crystallites than a conventional reduction in hydrogen flow at $653 \mathrm{~K}$. This is particularly evident for palladium catalysts: for Pd-IMP-653 K and Pd-IMP-MW the sizes of Pd crystallites (calculated from the XRD line broadening) are $2.2 \mathrm{~nm}$ and $4.4 \mathrm{~nm}$, respectively (see Table 1). Au crystallites deposited on Sibunit by impregnation are much larger $(15-17 \mathrm{~nm})$ for both monometallic gold catalysts-highly dispersed gold catalysts are difficult to prepare using carbon supports because carbon materials, being reducing agents, can react with $\mathrm{Au}^{3+}$ to form large gold particles during synthesis $[49,50]$. In all XRD profiles of bimetallic $\mathrm{PdAu} / \mathrm{C}$ catalysts, the (111) reflections are located between $\mathrm{Pd}$ and $\mathrm{Au}$, thus showing that some $\mathrm{Au}$ atoms were introduced into the Pd crystallite. A distinct peak asymmetry can be seen for the $\mathrm{PdAu}$ samples activated by a conventional thermal reduction in $\mathrm{H}_{2}$ at $653 \mathrm{~K} / 3 \mathrm{~h}$ : the right branches of the profiles are noticeably distorted by the presence of Pd-richer phases and the left branches by the presence of Au-richer phases. 


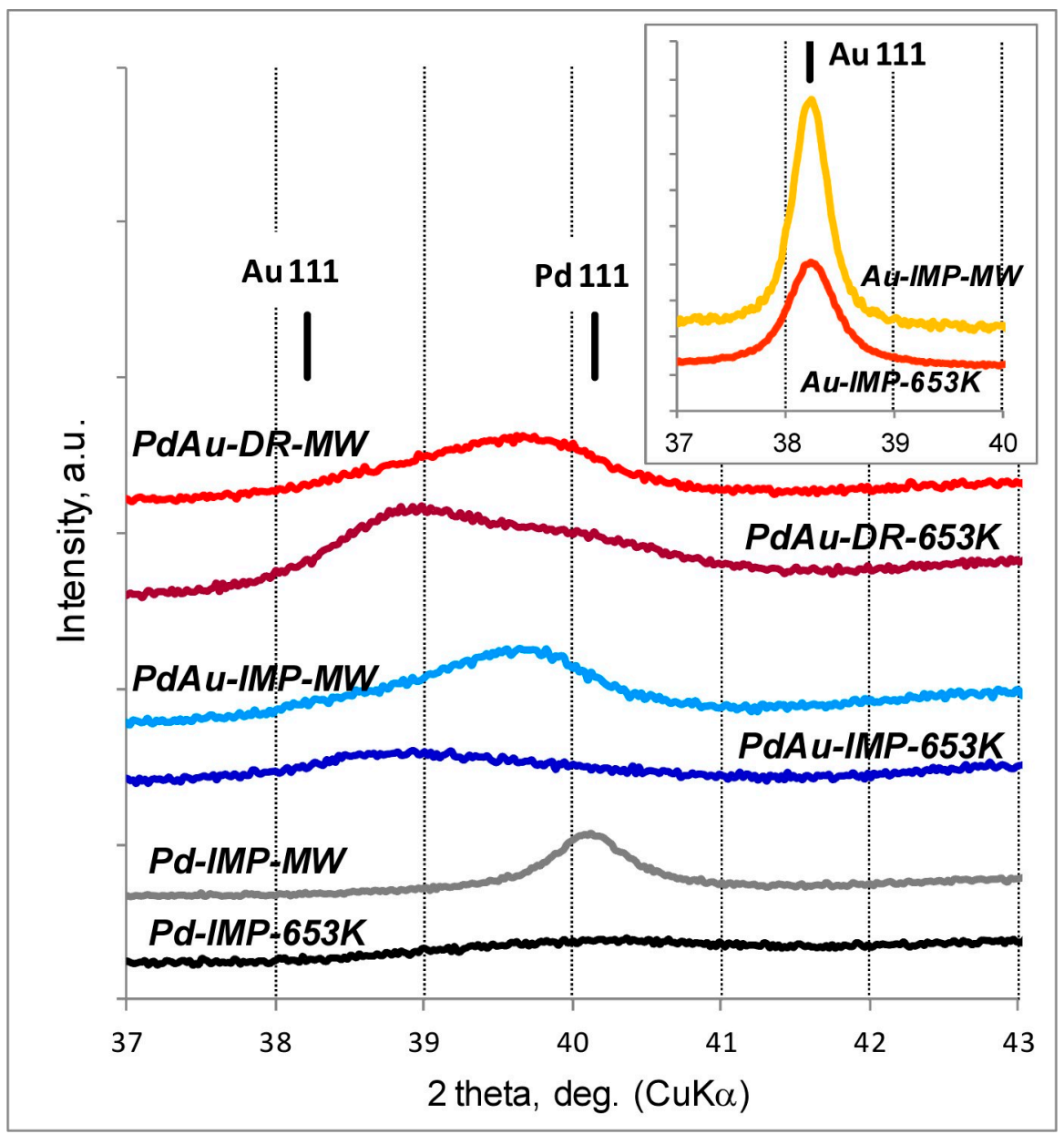

Figure 1. XRD profiles of Sibunit-supported Pd and Pd-Au catalysts after activation. Inset: XRD profiles from Au catalysts. For catalysts' code, see Table 1. Positions of (111) reflections of $f c c$ phases of palladium and gold are marked.

The decomposition of the (111) reflection profile into Voigt functions allowed us to estimate the presence of various $\mathrm{Pd}-\mathrm{Au}$ phases and an unalloyed palladium phase (Table 1). The atomic composition $\left(\mathrm{Pd}_{X} \mathrm{Au}_{100-\mathrm{X}}\right)$ of detected phases is based on the lattice parameter, calculated from the (111) reflection assuming Vegard's law. Indeed, the asymmetry of the profiles is caused by the coexistence of different $\mathrm{Pd}_{X} \mathrm{Au}_{100-\mathrm{X}}$ phases. Apart from the bimetallic $\mathrm{Pd}-\mathrm{Au}$ phases, the unalloyed palladium crystallite phase can be identified in both thermally activated in hydrogen catalysts. The Pd-Au catalysts, which had been activated by flash MW irradiation (1050 W/5 s), displayed a much higher degree of Pd-Au alloying: although the reflections are also slightly asymmetrical, they are shifted to a position corresponding to the nominal Pd and Au content of the alloy and monometallic phases are non-visible.

MW-irradiated Pd-Au samples always showed better homogeneity of the bimetallic phase than their conventionally treated counterparts. In the case of the catalyst PdAuDRMW, each of the X-ray reflections is almost symmetrical and can be described by two functions, corresponding to the two alloy compositions. For example, for the $\mathrm{PdAu}$ DR-MW catalyst, the presence of two phases was found, namely $\mathrm{Pd}_{77} \mathrm{Au}_{23}$ (dominant phase with a molar composition close do the nominal) and $\mathrm{Pd}_{26} \mathrm{Au}_{74}$. For the catalyst after reduction in hydrogen at $653 \mathrm{~K}$, the significant peak asymmetry was observed, and deconvolution of each of the $\mathrm{X}$-ray reflections gives three functions, corresponding to the two alloy compositions $\left(\mathrm{Pd}_{37} \mathrm{Au}_{63}\right.$ and $\left.\mathrm{Pd}_{89} \mathrm{Au}_{11}\right)$ and one unalloyed palladium phase. 
The results of $\mathrm{CO}$ chemisorption measurements confirmed the conclusions from XRD studies: monometallic palladium catalyst activated conventionally in $\mathrm{H}_{2}$ at $653 \mathrm{~K}$ is composed of small nanoparticles $\sim 2.8 \mathrm{~nm}$ in diameter, while in catalyst activated by MW radiation metal particles are about twice bigger $(\sim 5.3 \mathrm{~nm})$ (see Table 1$)$. A similar relationship is found for all tested catalysts: for catalysts activated by MW irradiation, metal particles are larger than for their equivalents activated thermally in hydrogen. As $\mathrm{CO}$ chemisorption measurements show, the addition of gold to the monometallic palladium catalyst significantly increases the metal particle size. However, one should consider that the particle size of $\mathrm{Pd}-\mathrm{Au}$ alloys can be overestimated by the chemisorption measurements since there is no chemisorption of $\mathrm{CO}$ on gold. Several problems affect the correctness of metallic particle size calculations from $\mathrm{CO}$ chemisorption for $\mathrm{Pd}-\mathrm{Au}$ alloy phases. For example, $\mathrm{Pd}-\mathrm{Au}$ particles can be formed by phases of different compositions. For each of these compositions, the stoichiometric $\mathrm{CO}_{\mathrm{ads}}:(\mathrm{Pd}+\mathrm{Au})$ ratio can be different and far from the value of 1.5 taken for pure palladium. For this reason, for $\mathrm{Pd}-\mathrm{Au}$ bimetallic catalysts, particle size calculations resulting from X-ray diffraction or TEM measurements shall be considered more accurate.

For XRD measurements, size estimation from a single peak is prone to considerable error, and the most likely volume-averaged crystal size for detected $f c c$ phases was estimated from several peak widths using a Williamson-Hall-like plot [51]. These values are listed in Table 1 and generally are lower than the estimates from CO chemisorption and higher than those resulting from the TEM experiments. The critical factor affecting the outcome of various measurements is rather broad crystal size distribution $h(R)$. The volume-weighted distribution $\left(h(R)^{*} R^{\wedge} 3\right)$ is shifted to higher $R$ and its average, as resulting from XRD, for typical lognormal distribution of sizes, as a rule, has a much larger value than average size estimated from TEM size histogram $(h(R)$ average). Additionally, TEM size statistics (defining $h(R)$ ) is much worse than that affecting XRD peak shape. Even fulfilling requirement to measure at least 500 particles (typically accepted for TEM size histograms) usually leads to an underestimation of a high size part of the distribution. However, adding to the histogram even one large particle per 2000 may significantly affect the volume-weighted average [52]. On the other hand, the XRD pattern is a build-up of contributions from millions of crystallites providing a more reliable average.

The size estimation from the $\mathrm{CO}$ chemisorption strongly depends on the adsorption stoichiometry. In fact, the ratio of size estimates obtained with chemisorption and XRD measurements increases with the particle size. It suggests that the $\mathrm{CO}$ adsorption stoichiometry is significantly higher for small particles as they expose to the CO more substantial fraction of edge and vertex atoms. It may also depend on the initial segregation profile in the bimetallic particle accepting that the self-diffusion (segregation) rate at the temperature of the chemisorption experiments $(308 \mathrm{~K})$ is negligible. The overall differences may suggest that a significant part of the metal surface does not bind $\mathrm{CO}$.

TEM measurements also confirmed the beneficial role of the MW radiation on a better distribution of both metals in the support for all Pd-Au catalysts, Figure 2.

It can be easily seen that the best $\mathrm{Pd}-\mathrm{Au}$ particle homogeneity was obtained for the PdAu-DR-MW catalyst. It should be stressed that just the change of the solvent for palladium and gold salt from water [48] to acetone during the preparation of the catalysts resulted in higher uniformity of the metallic phase in catalysts, both for MW-activated catalysts and for catalysts activated in $\mathrm{H}_{2}$ at $653 \mathrm{~K}$, whereby this improvement was more evident in the case of MW-irradiated catalysts. Our results confirmed the hypothesis that the application of MW irradiation stimulates the particle dipoles to intensify their rotations and vibrations, generates heat that rapidly dissipates throughout the sample volume because of the increased friction between molecules. Uniform heating results in a faster crystallization process [53] leading to the formation of homogenous PdAu alloys. It is worth noting that the $\mathrm{Pd}-\mathrm{Au}$ catalysts activated by $\mathrm{MW}$ irradiation have narrower particle distribution size (cf. diagrams in the right section of Figure 2). 

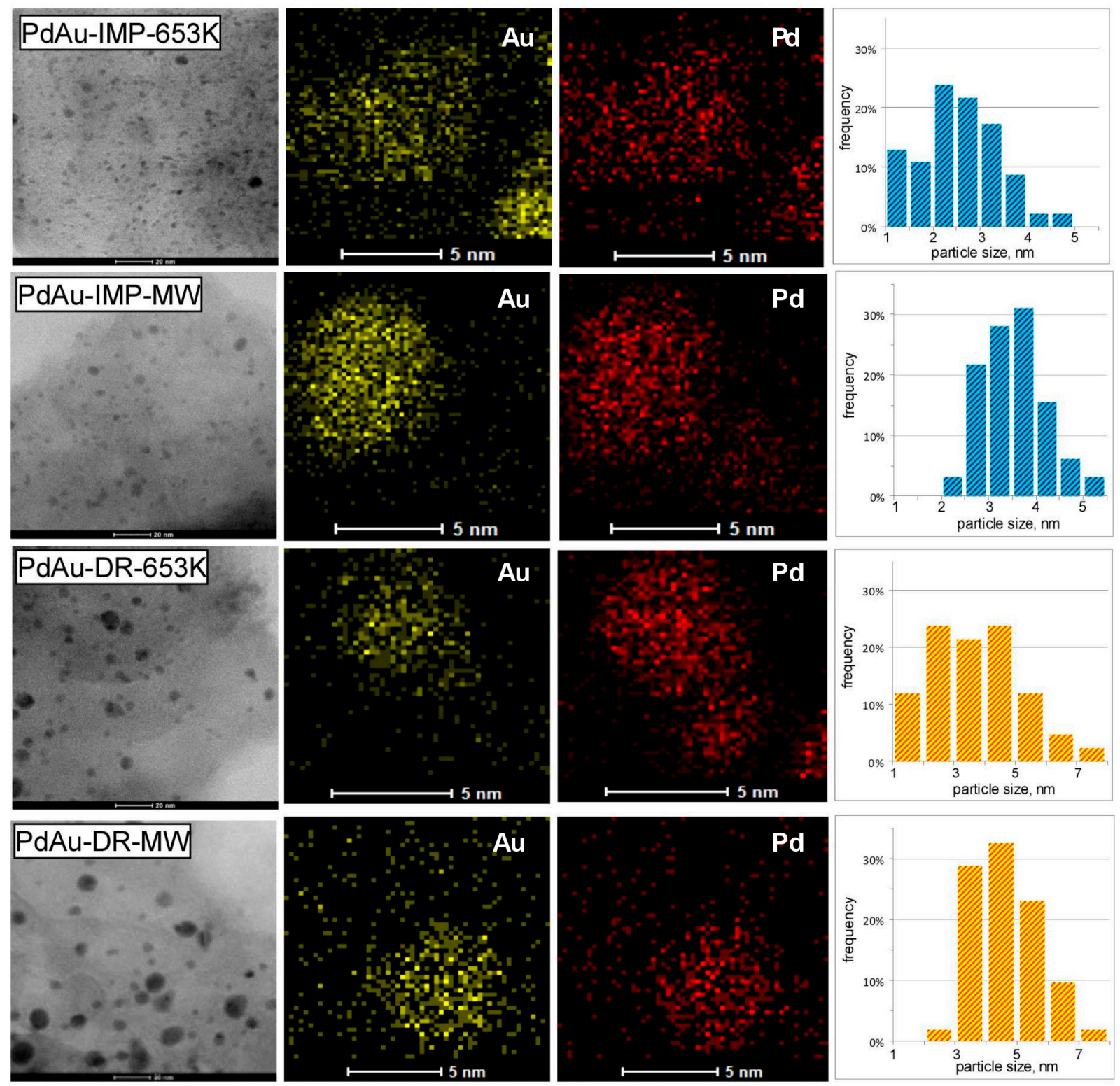

Figure 2. Representative TEM micrographs of $\mathrm{Pd}-\mathrm{Au}$ catalysts after activation in $\mathrm{H}_{2} / 653 \mathrm{~K}$ and after activation by $\mathrm{MW}$ irradiation: HAADF-STEM images (left section), EDX elemental mapping (central section), and particle size distribution (right section).

Temperature-programmed $\beta$-hydride phase decomposition (TPHD) study (Table 1 and Figure 3) is an advantageous technique for characterizing supported mono- and bi-metal Pd-based catalysts [40,54-56].

For monometallic palladium catalysts, the observed narrow and single TPHD peak implies the $\beta$-PdH decomposition from the palladium particles of a similar size. On the other hand, double/multiple and structured in shape TPHD peaks suggest the presence of a palladium phase characterized by a broader distribution of particle size [27]. 


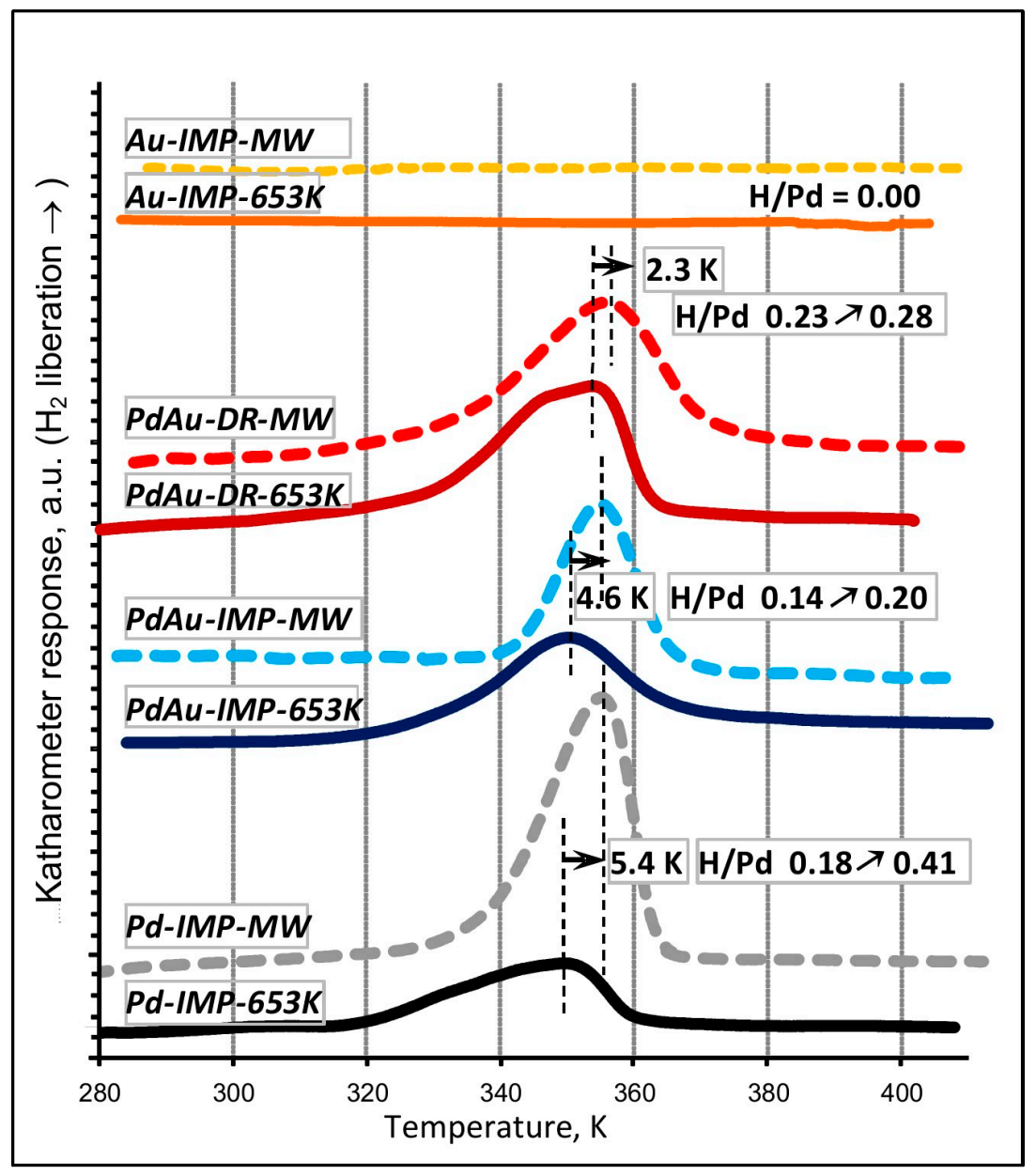

Figure 3. Temperature-programmed $\beta$-hydride phase decomposition (TPHD) profiles $\mathrm{Pd}-\mathrm{Au} / \mathrm{C}_{\text {Sibunit }}$ catalysts. Catalysts activated in $\mathrm{H}_{2} / 653 \mathrm{~K} / 3 \mathrm{~h}$-solid lines; catalysts activated by microwave irradiation $1050 \mathrm{~W} / 5 \mathrm{~s}$-dashed lines.

Additionally, a shift of peak maximum towards higher temperatures indicates the presence of bigger Pd particles. For two palladium catalysts, the hydride decomposition peak is shifted towards higher temperatures ( $349 \mathrm{~K}$ for Pd-IMP-653 K and $354.4 \mathrm{~K}$ for the Pd-IMP-MW). This shift is accompanied by an increase in the amount of hydrogen released $(\mathrm{H} / \mathrm{Pd}$ value is 0.18 and 0.41 , respectively), which can be explained by the presence of about twice bigger palladium nanoparticles in the Pd-IMP-MW compared to that in the commonly reduced the Pd-IMP-653 K catalyst, in agreement with the Pd size of $2.8 \mathrm{~nm}$ and $5.3 \mathrm{~nm}$, respectively (Table 1).

In the case of bimetallic Pd-Au catalysts, the TPHD experiment is a suitable method that allows for estimation of the degree of $\mathrm{Pd}$ and $\mathrm{Au}$ alloying. The introduction of gold (which itself does not form the hydride phase) to the palladium lattice increases the stability of the hydride phase and decreases the amount of released hydrogen [57]. The shift to a higher temperature of the hydride decomposition peak is accompanied by a decrease in the amount of released hydrogen, evidenced by an $\mathrm{H} / \mathrm{Pd}$ ratio, Table 1 . The lower $\mathrm{H} / \mathrm{Pd}$ value and higher decomposition temperature indicate that a significant amount of gold interacts with palladium in these catalysts. Simultaneously, in the case of catalysts activated by MW radiation, a shift in the maximum TPHD peaks towards higher temperatures is observed since this type of activation increases the size of metal crystallites. This increase in the size of metal crystallites is not as significant as for palladium catalysts, so the amount of hydrogen released from the hydrogen phase does not increase so significantly: for PdAu-DR-653 K and PdAu-DR-MW catalysts $\mathrm{H} / \mathrm{Pd}$ are 0.23 and 0.28 , respectively. It 
should also be stressed that for all catalysts, both monometallic palladium and bimetallic palladium-gold catalysts, the peaks of the $\beta$-hydride phase decomposition are considerably larger, much more symmetrical and have only one maximum for the catalysts activated by MW irradiation than for those thermal activated in $\mathrm{H}_{2}$ flow. Such effects prove that MW-radiation-activated catalysts are more homogeneous both in terms of size of metal particles and in terms of quality of $\mathrm{Pd}-\mathrm{Au}$ alloys.

We have also performed complementary electrochemical measurements using cyclic voltametry $(\mathrm{CV})$ that allows for more accurate analysis of the structure and surface composition of the synthesized bimetallic particles. The CV measurements have already been applied for characterization supported metal particles such as PdAu/C [58], PdIr/C [59], $\mathrm{Pd}-\mathrm{Au}-\mathrm{Pt} / \mathrm{C}$ [60] and various bimetallic films, for instance $\mathrm{Pd}-\mathrm{Au}$ [61]. The hydrogen sorption/desorption process and the surface fractions of individual metal components have been studied. Metal properties (metal-to-metal bonding energy, hydrogen adsorption strength, ability to form metal hydrides) as well as the way the metal components are arranged on the surface and in particle volume, and the ability for hydrogen penetration inside the particles have been studied [62-64]. It is well known that Pd-containing systems, with the addition of another metal, exhibit completely different hydrogen sorption properties than those characteristic for Pd. For example, the hydrogen gas absorption measurements showed a drastic decrease in hydrogen sorption with increasing Au content in the $\mathrm{Pd}_{\mathrm{x}} \mathrm{Au}_{100-\mathrm{x}}$ nanoparticles (ca. $8 \mathrm{~nm}$ in size), up to ratio $=0.03 \mathrm{H} / \mathrm{PdAu}$ for $\mathrm{Pd}_{50} \mathrm{Au}_{50}$ composition. This drastic decrease in hydrogen absorption has been related to a solidsolution type of $\mathrm{Pd}-\mathrm{Au}$ structure, where $\mathrm{Pd}$ and $\mathrm{Au}$ atoms are homogeneously mixed at the atomic level. Electrochemically obtained results for the thin $\mathrm{Pd}-\mathrm{Au}$ films on electrodes also showed reduced hydrogen capacity with a growing amount of Au. The hydrogen capacity of $0.75 \mathrm{H} / \mathrm{Pd}$ for pure Pd decreased to ca. $0.4 \mathrm{H} / \mathrm{PdAu}$ at $30 \% \mathrm{Au}$ and ceased (reached zero) at 60-70\% Au [65]. A similar effect has been observed for thin films of other Pd-based alloys such as PdRh, PdRu [64], Pd-Cu [66], as well as carbon-supported PdPt nanoparticles [61].

The CV curve presented in the upper part of Figure 4 has a typical shape for the $\mathrm{Pd} / \mathrm{C}$ catalysts registered in acid solutions. Two areas are marked on this shape: I, area of desorption of hydrogen (which previously diffused into the palladium structure, forming $\beta$-hydride) and II, reduction region, where reduction of the palladium oxidized species occurs. The enlarged image of these two potential regions are shown for all tested $\mathrm{Pd}$ and PdAu catalysts in figures Ia-Ic and IIa-IIc. The CV profiles of Pd/C catalyst show the evident two peaks due to hydrogen absorption/desorption, the first at more negative potential (9.1-0.2 V vs. RHE) originated mainly from the oxidation of hydrogen from the $\beta$-PdH hydride phase. The second peak at more positive potential (ca. $0.28 \mathrm{~V}$ vs. RHE) corresponds to the desorption (electrooxidation) of adsorbed hydrogen at the surface. No hydrogen adsorption/desorption peaks on the $\mathrm{Au} / \mathrm{C}$ catalyst were observed, consistent with the literature data [65].

The CV profiles of both monometallic palladium catalysts (thermally activated by hydrogen, Pd-IMP-653 K, and activated by MW treatments, Pd-IMP-MW) are very similar. The situation is different for PdAu bimetallic catalysts as the shape of hydrogen desorption peaks (Figure $4(\mathrm{Ib}, \mathrm{Ic})$ ) differ from those on pure Pd/C catalyst (Figure 4(Ia)). 


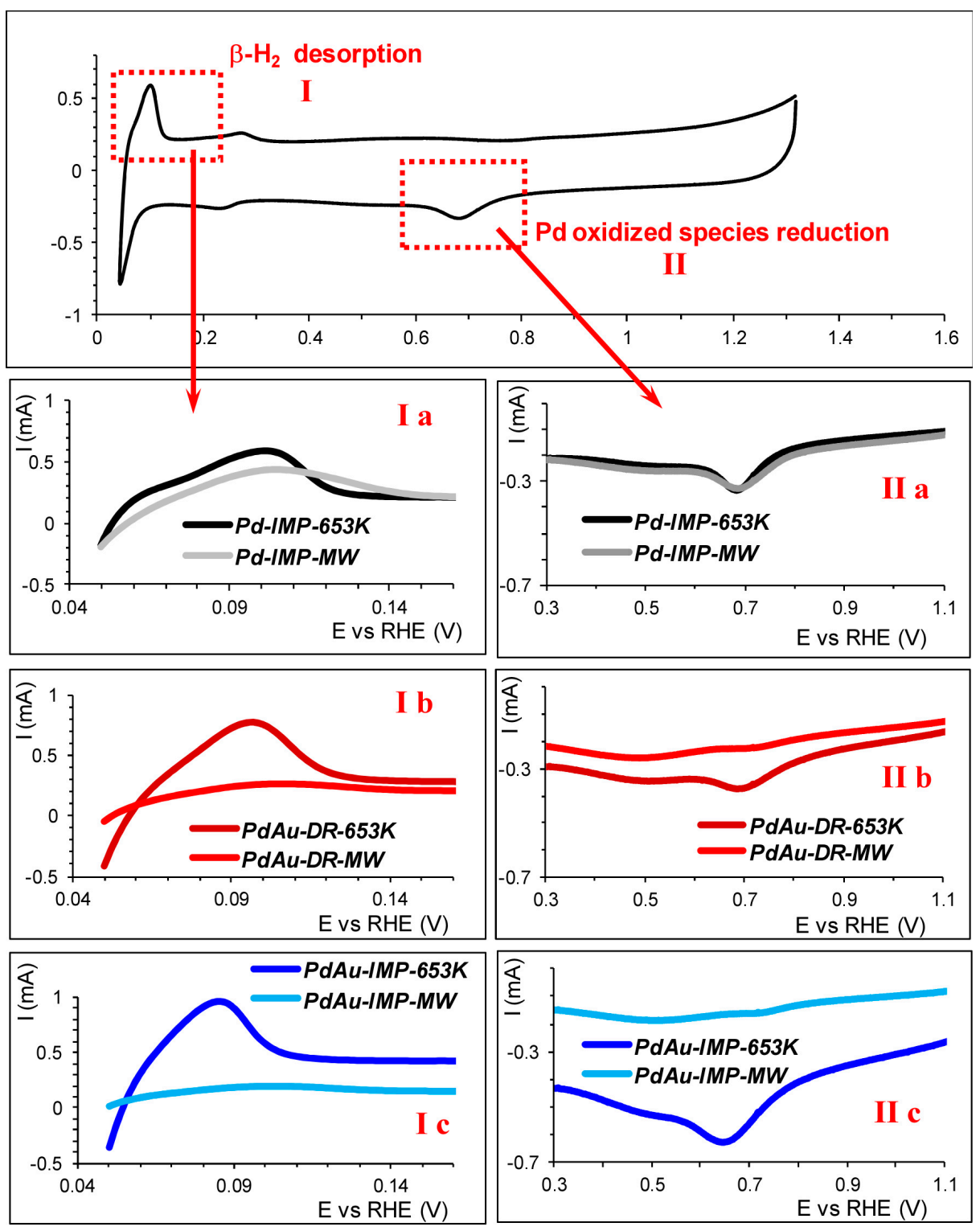

Figure 4. The cyclic voltammograms (CV) experiments. (I)—typical profile for the Pd catalysts; (Ia-Ic)—desorption regions for Pd-IMP, PdAu-DR and PdAu-IMP catalysts after activation; (IIaIIc)-reduction regions for Pd-IMP, PdAu-DR and PdAu-IMP catalysts after activation.

Since the amount of each catalyst was the same on the electrode and consequently, the amount of palladium was the same, the lower currents measured in the case of both MW-activated catalysts, PdAu-DR-MW, and PdAu-IMP-MW, could be related to the lower ability towards the Pd-hydride formation. The effect is much weaker on the $\mathrm{H}_{2}$-activated catalysts PdAu-IMP-653 K and PdAu-DR-653 K as the hydrogen desorption currents do not radically differ from that for pure Pd. However, for conventionally activated PdAu-IMP$653 \mathrm{~K}$ catalysts, the hydrogen desorption peak is shifted to lower potentials relative to pure $\mathrm{Pd}(0.085 \mathrm{~V}$ against $0.103 \mathrm{~V}$ vs. RHE, respectively) which might be related to Pd electronic modification. Thus, a distinct inhibition of the Pd-hydride formation observed in both MWactivated catalysts could indicate more effective $\mathrm{Pd}-\mathrm{Au}$ alloying in these catalysts compared to their counterparts synthesized by the thermal $\mathrm{H}_{2}$-activation procedure, consistent with the outcomes of the TPHD measurements (vide supra).

The magnified views of $\mathrm{CV}$ profiles in the potential region corresponding to the reduction of oxidized surface species are displayed in Figure 4(IIa-IIc). In the CV of $\mathrm{Pd} / \mathrm{C}$ catalysts (Figure 4(IIa)), the peak at the potential of $0.682 \mathrm{~V}$ vs. RHE is measured 
corresponding to the reduction of palladium oxide. A small peak at the potential of ca. $0.5 \mathrm{~V}$ arises from the reduction of oxidized carbon groups, as it was registered in a blank experiment using pure carbon support. For Pd-Au catalysts, well-defined single surface oxides reduction peaks can be seen, and their potentials are located between the reduction of Pd (0.682 V, RHE) and Au (1.09 V, RHE). This effect, according to Rand et al. [67], indicates that the surface of the bimetallic PdAu nanoparticles consists of Pd and $\mathrm{Au}$ components. Moreover, according to Rand [67], in the case of bimetallic systems, a single reduction peak indicates the homogeneous composition of the bimetallic surface. The presence of multiple signals due to surface oxide reduction indicates surface heterogeneity, i.e., the existence of separate "areas" of different compositions.

The surface fraction of $\mathrm{Pd}$ and $\mathrm{Au}$ could be estimated from the potential of oxide reduction peak based on a linear dependence of the potential of surface oxide reduction peak $\left(E_{P, A l l o y}\right)$ and the surface composition [67]:

$$
E_{P, A L L O Y}=X_{P d} E_{P, P d}+X_{A u} E_{P, A u}
$$

where $E_{P, P d}, E_{P, A u}$ are the oxide reduction peak potentials for the pure $\mathrm{Pd} / \mathrm{C}$ and $\mathrm{Au} / \mathrm{C}$ catalysts and $X_{P d}$ and $X_{A u}$ are the surface fractions of $P d$ and $A u$, respectively.

From the potential of the oxide reduction of $0.695 \mathrm{~V}$ and $0.716 \mathrm{~V}$ vs. RHE in the $\mathrm{PdAu}-\mathrm{DR}-653 \mathrm{~K}$ and PdAu-DR-MW catalysts (Figure 4(IIb)) the surface fractions $\mathrm{Au} / \mathrm{Pd}$ are calculated to be $0.02 / 0.98$ and $0.07 / 0.93$, respectively, thus showing more $\mathrm{Au}$ in the surface of MW-activated catalyst. The potential of the reduction peak registered for the PdAu-IMP-653 K catalyst ( $0.670 \mathrm{~V}$ vs. RHE) was almost equal to that in pure Pd, thus suggesting no $\mathrm{Au}$ in its surface shells. In contrast, the peak potential of $0.726 \mathrm{~V}$ vs. RHE for its counterpart obtained by MW activation (PdAu-IMP-MW) resulted in the surface fraction of $\mathrm{Au} / \mathrm{Pd}=0.1 / 0.9$ indicating the highest surface content of $\mathrm{Au}$ among all the studied catalysts. In the context of the bulk atomic ration $\mathrm{Au} / \mathrm{Pd}=15 / 85$, this suggests that the surface of studied $\mathrm{PdAu}$ particles is enriched in $\mathrm{Pd}$, and that the ratio depends on the procedure of catalysts preparation/activation.

\subsection{Catalytic Behaviour of $\mathrm{Pd}-\mathrm{Au} / \mathrm{Sibunit}$ in $\mathrm{CCl}_{4}$ Hydrodechlorination}

The total conversion changes and final product distribution (after $\sim 22 \mathrm{~h}$ time-onstream), including the selectivity towards desired products (i.e., methane and C2-C4 hydrocarbons), chloroform (significantly less harmful than $\mathrm{CCl}_{4}$ ), and chlorinated $\mathrm{C} 2$ hydrocarbons (undesired products) for $\mathrm{HdCl}$ of $\mathrm{CCl}_{4}$ are shown in Figure 5.

From the measurements characterizing the structure and composition of catalysts, it follows that the homogeneity of the alloy structure is strongly dependent on the activation method: for each pair of the catalysts (catalyst activated in $\mathrm{H}_{2} / 653 \mathrm{~K}$ and its counterpart activated by MW irradiation) better homogeneity has always been for the latter catalyst. As a result of the improved homogeneity, better catalytic properties in $\mathrm{HdCl}$ of $\mathrm{CCl}_{4}$, in terms of resistance to deactivation in time-on-stream and selectivity to desired products, were observed for catalysts subjected to microwave irradiation. 

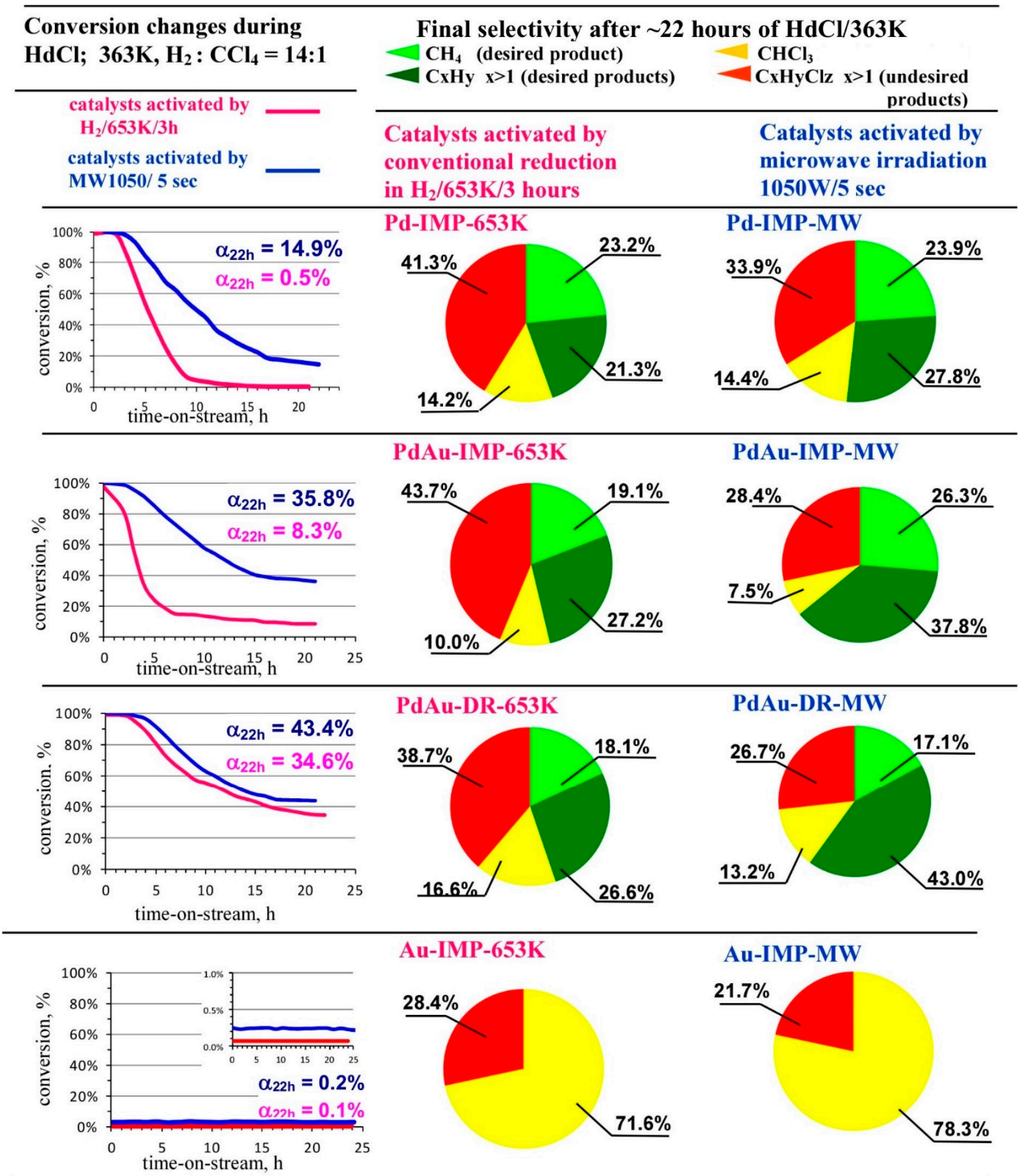

Au-IMP-653K

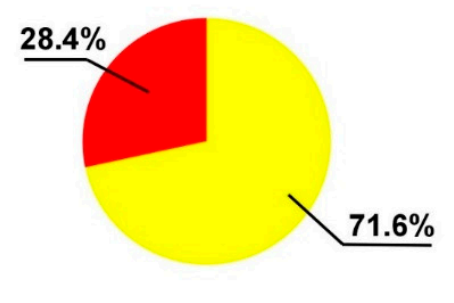

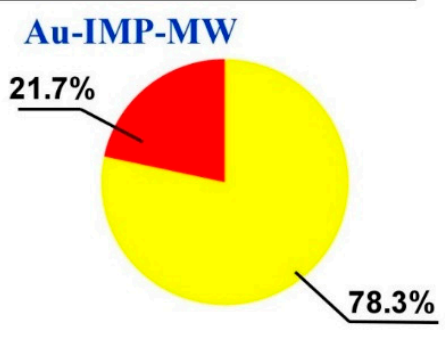

Figure 5. Total conversion changes in time-on-stream (left section, line graphs) and final selectivities (right section, pie charts) after $\sim 22 \mathrm{~h}$ time-on-stream in $\mathrm{CCl}_{4}$ hydrodechlorination at $363 \mathrm{~K}$ on carbon Sibunit-supported $\mathrm{Pd}, \mathrm{PdAu}$ and $\mathrm{Au}$ catalysts. Au catalysts. Inset: the y-axis is expanded by a factor of 100 compared to the main axis.

Chemisorption and XRD studies showed that catalysts after activation by MW irradiation have larger metal crystallites than catalysts after thermal activation in hydrogen, with this increase being the highest for monometallic Pd (Table 1). Interestingly, all the palladium and bimetallic PdAu catalysts activated by MW irradiation exhibited higher resistance to deactivation than their counterparts obtained by $\mathrm{H}_{2}$ activation. In the case of monometallic Pd catalysts, this effect is evidenced by the final conversions $\left(\alpha_{22 \mathrm{~h}}\right)$ of $0.5 \%$ and $14.9 \%$ for catalyst Pd-IMP-653 K and Pd-IMP-MW, respectively (Figure 5). This result is rationalized in terms of a palladium dispersion effect, and it is in line with earlier works 
on $\mathrm{Pd} / \mathrm{C}$ catalysts $[27,28]$, pointing at better deactivation resistance in the gas phase $\mathrm{HdCl}$ process for the catalysts with the Pd particles of larger size. Additionally, MW activation resulted in a decrease of final selectivity towards $\mathrm{C} 2$ chlorohydrocarbons (the undesired products of $\mathrm{HdCl}$ of $\mathrm{CCl}_{4}$ ) to the level $33.9 \%$, compared to the $41.3 \%$ selectivity obtained for Pd-IMP-653 K catalyst.

Regardless of the activation method, gold is almost inactive in this reaction, and the monometallic $\mathrm{Au} / \mathrm{C}$ catalysts showed only negligible activity in $\mathrm{HdCl}$ of $\mathrm{CCl}_{4}: \alpha_{22 \mathrm{~h}}=0.1 \%$ and $\alpha_{22 \mathrm{~h}}=0.2 \%$ for Au-IMP-653 K and Au-IMP-MW, respectively. This is in line with the previously reported catalytic activity of gold: poorly dispersed gold particles were only slightly active in $\mathrm{HdCl}$ of 2,4-dichlorophenol [68]. However, although gold itself is almost inactive in the $\mathrm{HdCl}$ of $\mathrm{CCl}_{4}$, its addition to palladium catalysts introduces substantial changes in the catalytic behavior, and the catalytic properties of $\mathrm{Pd}-\mathrm{Au}$ catalysts strongly depend on the quality of $\mathrm{Pd}-\mathrm{Au}$ alloying.

It is evident from Figure 5 that catalyst Pd-IMP653 K, which contains quite small Pd particles $(<3 \mathrm{~nm})$, suffers from rapid deactivation (what is in line with other reports $[69,70])$. One of the reasons for the observed deactivation of the catalyst are $\mathrm{C}_{2} \mathrm{H}_{\mathrm{y}} \mathrm{Cl}_{\mathrm{z}}$ dimers (undesired products formed due to the subsequent reactions taking place during $\mathrm{HdCl}$ of $\mathrm{CCl}_{4}$ ), which accumulate on the surface of palladium catalysts [5]. A similar situation is observed for the PdAu-IMP-653 K catalyst, which contained a PdAu alloy with a high gold content and small unalloyed Pd particles (Table 1). Furthermore, the distribution of the final product is almost the same for both catalysts. Therefore, it seems evident that the reaction must be regulated mainly by the presence of unalloyed palladium, with a minor contribution of the Au-rich phase. After an initial period of relatively effective action, the unalloyed palladium leads to rapid catalyst deactivation. The activation by MW irradiation results in the disappearance of an unalloyed palladium phase and a homogeneous alloy in the PdAu-IMP-MW catalyst with near nominal gold content. As a result, the resistance of this catalyst to deactivation increases and the final activity and selectivity to the desired reaction products are significantly improved.

Initial conversion levels of $\mathrm{HdCl}$ of $\mathrm{CCl}_{4}$ on all tested catalysts (except Au catalysts) were close to $100 \%$ and then the catalysts were deactivated to variable degrees, reaching after about $22 \mathrm{~h}$ stable properties. This deactivation was reduced for PdAu bimetallic catalysts and was the lowest for catalyst PdAu-DR-MW, showing the best homogeneity of $\mathrm{Pd}-\mathrm{Au}$ alloy phase. Therefore, possible synergistic effects associated with $\mathrm{Pd}-\mathrm{Au}$ alloying will be discussed in terms of final selectivities and conversions. As mentioned earlier, catalysts Pd-IMP-653 K and PdAu-IMP-653 K, which comprise of rather small unalloyed palladium particles, deactivated quickly on stream. The positive effect of gold was seen for the rest of $\mathrm{Pd}-\mathrm{Au}$ catalysts, which exhibited much better, although not equal resistance to deactivation (Figure 5, left section-total conversion changes in time-on-stream).

A comparison of these catalytic results with the homogeneity and phase composition of Pd-Au alloys (Table 1 and Figures 1-3) leads to a direct correlation between resistance for deactivation with the quality of the $\mathrm{Pd}-\mathrm{Au}$ alloy. In this respect, the best catalyst was $\mathrm{PdAu}-\mathrm{DR}-\mathrm{MW}$, consisting predominantly a homogeneous alloy phase $\operatorname{Pd}_{77} \mathrm{Au}_{23}$, with the absence of unalloyed palladium. Our data also suggest a vast increase in the selectivity towards hydrocarbons, which are the most desired reaction products, upon homogeneous alloying of gold and palladium. When considering methane and longer hydrocarbons altogether, the advantage of well-alloyed PdAu-DR-MW catalyst over conventionally activated PdAu-DR-653 K catalyst is clear with selectivities of about $60 \%$ for the former and $45 \%$ for the latter.

The catalysts after $\mathrm{HdCl}$ of $\mathrm{CCl}_{4}$ were tested by XRD and TPH-MS measurements. The comparison of XRD spectra of the initial (activated) (Figures 6a and 7(a1,b1)) and spent samples (Figures $6 \mathrm{~b}$ and $7(\mathrm{a} 2, \mathrm{~b} 2))$ provides additional information about the composition of active phase in $\mathrm{Pd}$ and $\mathrm{PdAu} / \mathrm{C}$ catalysts. 


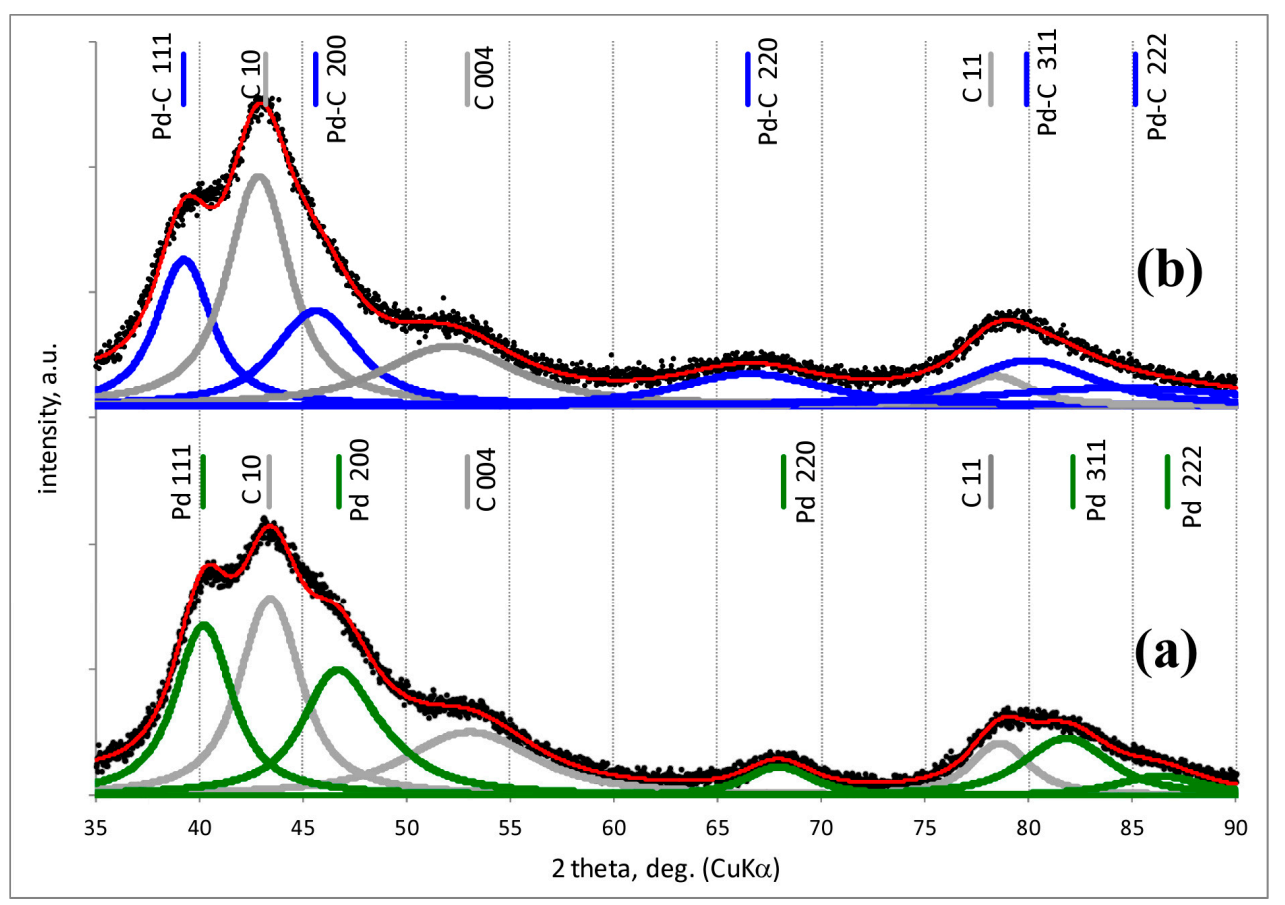

Figure 6. XRD analysis of catalyst Pd-IMP-653 K: (a) after activation in $\mathrm{H}_{2} / 653 \mathrm{~K} / 3 \mathrm{~h}$; (b) after activation in $\mathrm{H}_{2} / 653 \mathrm{~K} / 3 \mathrm{~h}$ and hydrodechlorination of $\mathrm{CCl}_{4} / 363 \mathrm{~K}$. The obtained XRD profiles (black dots) were fitted to an analytical function of the PEARSON-VII type (grey lines-components responsible for carbon content; blue lines and green lines-components responsible for PdCx and $\mathrm{Pd}$ content, respectively). Basic XRD reflections from $\mathrm{Pd}, \mathrm{PdCx}$ and carbon are marked.

Carbiding of palladium-containing catalysts during hydrodechlorination reactions is a well-known phenomenon: carbon (from the $\mathrm{CCl}_{4}$ molecule after stripping off all chlorine atoms) penetrates the palladium crystal lattice, occupies octahedral voids to form palladium-carbon solutions up to a $\mathrm{PdC}_{0.13}$ [71-73]. The extent of carbon incorporation can be a measure of $\mathrm{Pd}-\mathrm{Au}$ homogeneity as carbon, analogously to hydrogen, should be less soluble in well-mixed $\mathrm{Pd}-\mathrm{Au}$ alloys than in pure $\mathrm{Pd}$. Therefore, the comparison of XRD spectra for catalysts, before and after the $\mathrm{HdCl}$ reaction, should furnish additional information on the composition of an active phase of $\mathrm{Pd}-\mathrm{Au} / \mathrm{C}$ catalysts. The obtained XRD profiles were fitted to an analytical function of the PEARSON-VII type; an asymmetric band from turbostratic carbon (C10 and C11) was described via SplitParsonVII function, and the second-order carbon sheet stack peak (C004) was fitted to a single PearsonVII profile.

Figure 6 shows, using the example of a Pd-IMP-653 K catalyst, how carburizing affects the diffraction profile of a monometallic palladium catalyst. For this catalyst after activation in $\mathrm{H}_{2} / 653 \mathrm{~K} / 3 \mathrm{~h}$, the positions of all Pd reflectors are typical for this metal, e.g., for the reflex $\operatorname{Pd}(111) 2 \Theta=40.2$, for $\operatorname{Pd}(200) 2 \Theta=46.7$. When carbon is dissolved in palladium during $\mathrm{HdCl}$ catalytic test, the Pd lattice constant increases from $\sim 0.389$ to $\sim 0.399 \mathrm{~nm}$ [74-76], which is evidenced by a downward shift of the reflections in the XRD pattern. For this reason, in the diffraction pattern of spent Pd-IMP-653 K catalyst after $\sim 22 \mathrm{~h}$ of reaction, the palladium reflections disappeared, whereas the reflections of $\mathrm{PdC}$ phase are registered, e.g., for $\operatorname{PdC}(111) 2 \Theta=38.9^{\circ}$, and for $\operatorname{PdC}(200) 2 \Theta=45.9^{\circ}$. 


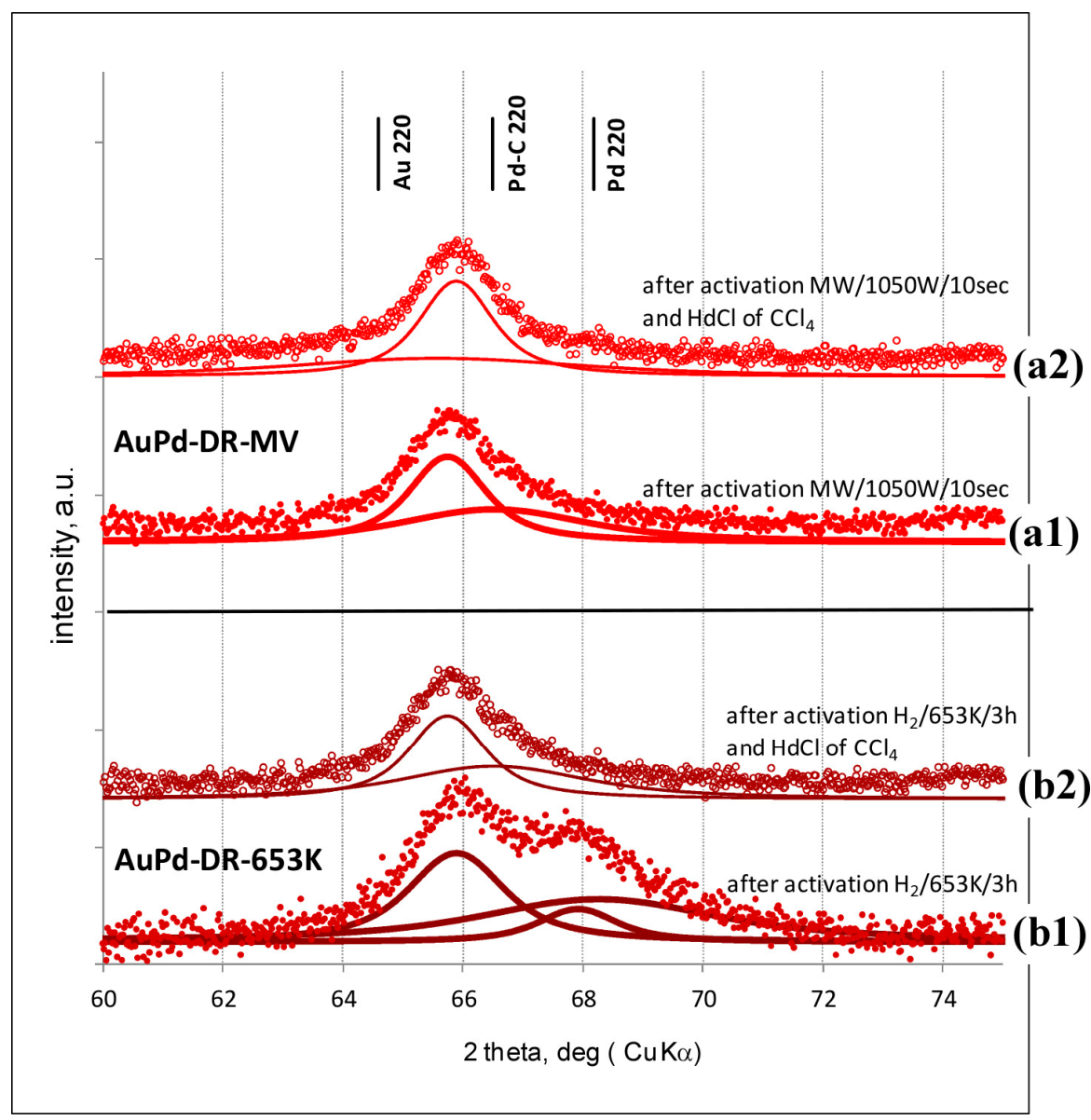

Figure 7. XRD profiles in the vicinity of the (220) reflection for catalysts PdAu-DR. Upper part: PdAu-DR-MW after activation by MW irradiation (a1) and after use in $\mathrm{HdCl}$ of $\mathrm{CCl}_{4}$ (a2); bottom part: PdAu-DR-653 K after thermal activation in $\mathrm{H}_{2}$ (b1) and after use in $\mathrm{HdCl}$ of $\mathrm{CCl}_{4}$ (b2).

The catalysts' patterns for catalysts PdAu-DR-653 K and PdAu-DR-MW, prepared by direct redox method then activated in different ways, are compared analogously in Figure 7. Here we focus on a fragment of the diffractogram only in the neighborhood of (220) reflections of $\mathrm{Au}, \mathrm{Pd}$ and PdC because the background from the Sibunit carbon is very flat in this diffraction range. It is seen that very good, although not perfect, alloying was achieved in the case of catalyst PdAu-DR-MW (Figure 7(a1)), where a relatively symmetric diffraction profile was obtained. Decomposition of the (200) reflection profile into Pearson VII-type functions allowed us to estimate the presence of two Pd-Au phases (Table 1), with a phase of close to the nominal composition being dominant, i.e., $\mathrm{Pd}_{77} \mathrm{Au}_{23}$ being dominant. The PdAu-DR-653 K catalyst shows a significant peak asymmetry: the presence of two additional phases ( $\mathrm{Pd}$ and $\mathrm{Pd}$-richer phases) noticeably distorts the right-hand side of the reflex from a dominant Pd-Au alloy phase (Figure 7(b1)).

It should be stressed that the PdAu-IMP catalyst which had been prepared by incipient wetness impregnation displayed a much lower degree of $\mathrm{Pd}-\mathrm{Au}$ alloying than the sample prepared by the direct redox reaction (Figure 1 and Table 1 ). The shift of XRD reflections, which was observed for the palladium catalyst after the $\mathrm{HdCl}$ reaction (Figure 6), is also observed for the PdAu catalyst. Figure 7(a2,b2) exemplifies this shift for two PdAu catalysts prepared by direct redox reaction, one activated by MW irradiation (a2), and the second by a thermal reduction in $\mathrm{H}_{2}$ (b2). The XRD reflections of used (spent) catalysts, especially in case of a PdAu-DR-653 K sample, are much more symmetric than in the initial catalysts after activation. Carbon dissolution in $\mathrm{Pd}$ (or Pd -rich alloys) as an effect of carbiding during $\mathrm{HdCl}$ of $\mathrm{CCl}_{4}$ must bring about more narrow diffraction 
profiles because $\mathrm{Au}(200)$ reflection (at $2 \Theta=44.3^{\circ}$, for $\mathrm{CuK}_{\alpha}$ radiation) is closer to $\mathrm{PdCx}$ (200) $\left(\right.$ at $\left.2 \Theta=45.9^{\circ}\right)$ than to the $\operatorname{Pd}(200)\left(\right.$ at $\left.2 \Theta=46.7^{\circ}\right)$. For PdAu-DR-MW catalyst, the profiles of spent and initial catalysts are very similar. After activation, this catalyst showed good alloy homogeneity and did not contain a non-alloyed monometallic palladium phase, carburisation of which could cause the most significant differences in the diffraction profiles of the catalyst after activation and after $\mathrm{HdCl}$ of $\mathrm{CCl}_{4}$.

Temperature programmed hydrogenation (TPH-MS) of used catalysts (Figure 8) shows that post-reaction deposits consist mainly chlorine-containing species (which appear in the mass spectra at 500-850 K) and significantly smaller amounts of carbonaceous materials, which are hydrogenated off at higher temperatures (650-1050 K).

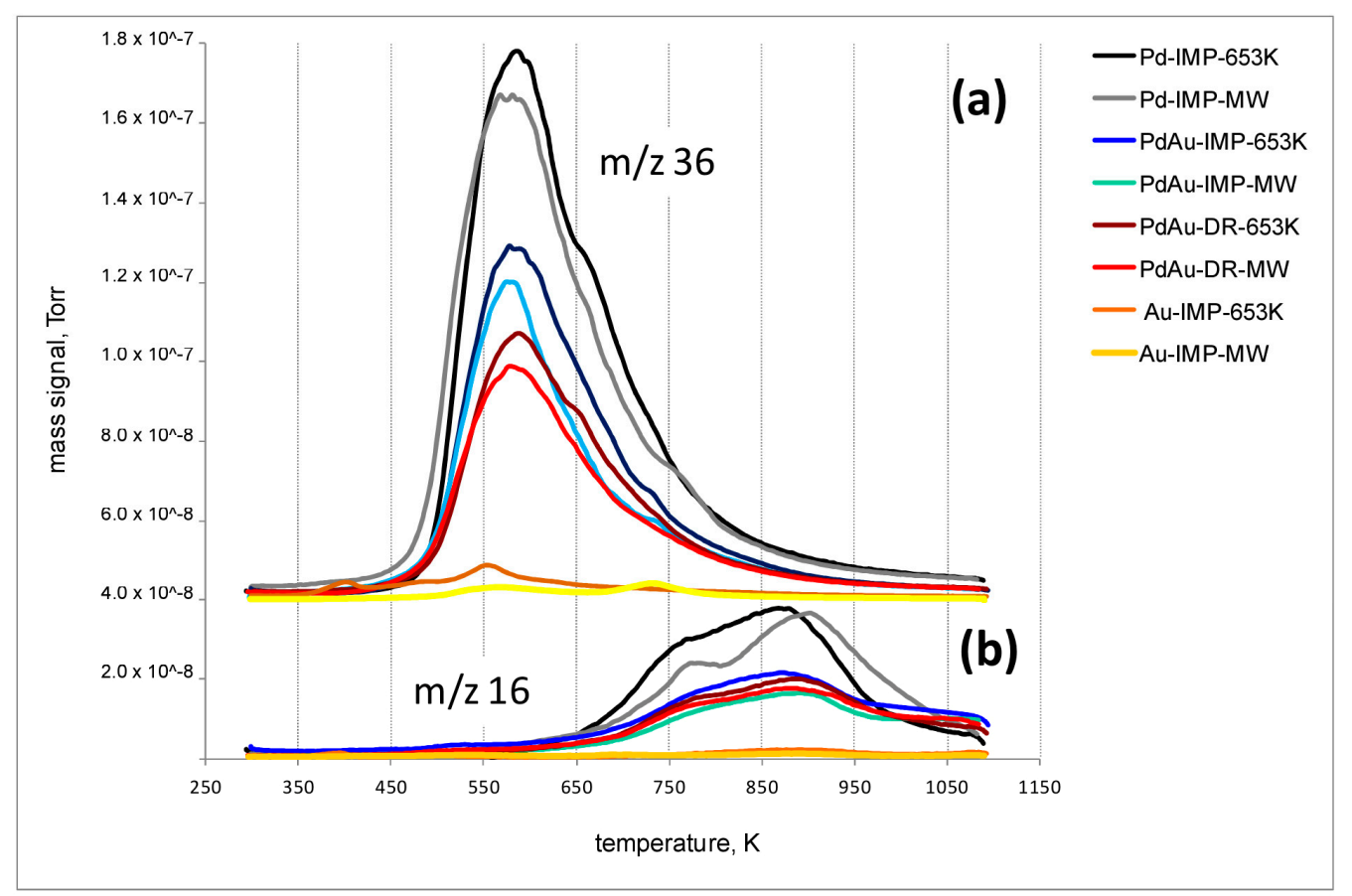

Figure 8. Temperature-programmed hydrogenation profiles of post-reaction deposits from carbon Sibunit supported Pd, PdAu and Au catalysts: (a) $\mathrm{HCl}(\mathrm{m} / z$ 36) evolution, (b) methane $(\mathrm{m} / z$ 16) evolution.

The highest content of both types of deposits was found in the case of monometallic palladium catalysts. The addition of gold to these catalysts resulted in a significant decrease in the amount of deposits. It is a rule that for each pair of the $\mathrm{PdAu}$ catalysts (catalyst activated thermally in hydrogen vs. its equivalent activated by MW irradiation), a smaller amount of the deposits was for the latter. The second finding is that the more homogeneous the $\mathrm{Pd}-\mathrm{Au}$ alloy is, the less deposit remains on the catalyst. The PdAu-DR-MW catalyst, which showed the best homogeneity of $\mathrm{Pd}-\mathrm{Au}$ alloy phase, contained the smallest amount of deposit.

As mentioned earlier, monometallic palladium catalysts quickly deactivate as a result of carbiding of palladium during the reaction: the $\mathrm{C} 1$ adspecies which are formed after stripping off chlorine from $\mathrm{CCl}_{4}$ molecules swiftly migrate into Pd bulk. When all $\mathrm{Pd}$ turns into $\mathrm{PdC}_{\mathrm{x}}$, its surface becomes less active in the $\mathrm{H}_{2}$ dissociation, and dissociatively adsorbed $\mathrm{CCl}_{4}$ is not easily hydrogenated; hence the reaction slows down. Previous studies on hydrodechlorination reactions show that the surface chloride species, which are formed as intermediates during dissociative adsorption of $\mathrm{CCl}_{4}$, oxidizes palladium on the catalytic surface generating active sites for the oligomerization process [69]. Metal- $\mathrm{Cl}$ bonds are much weaker in the case of gold than in the case of palladium [77], so introducing gold to palladium must decrease the bonding of chloride species. Because of weaker bonds, the 
removal of surface chlorine (as $\mathrm{HCl}$ by interaction with hydrogen which is in excess in the gas phase) is easier for bimetallic $\mathrm{Pd}-\mathrm{Au}$ surface than for $\mathrm{Pd}$ surface. Such an explanation is in qualitative agreement with the mechanism of hydrodechlorination reported by Chen et al. [78] who suggested that for $\mathrm{HdCl}$ of $\mathrm{CH}_{4-x} \mathrm{Cl}_{\mathrm{x}}(\mathrm{x}=1-4)$ compounds on a $\mathrm{Pd} /$ carbon catalyst, the irreversible scission of the first $\mathrm{C}-\mathrm{Cl}$ bond in the adsorbed $\mathrm{CCl}_{4}$ molecule is the rate-determining step. Much smaller amounts of surface chlorine species on the surface of $\mathrm{Pd}-\mathrm{Au}$ catalysts during $\mathrm{HdCl}$ would as well explain their better selectivity to the desired hydrocarbons products than to undesired ones (i.e., chlorine-containing compounds).

\section{Conclusions}

We have shown that application of a flash MW irradiation $(1050 \mathrm{~W} / 5 \mathrm{~s}$.$) as an$ activation step in the preparation of $\mathrm{PdAu} / \mathrm{C}_{\text {Sibunit }}$ bimetallic catalysts provides the active phase of high metallic homogeneity, way higher than obtained in a conventional thermal activation in hydrogen flow $(653 \mathrm{~K} / 3 \mathrm{~h})$.

The use of acetone solutions of metal precursor salts instead of aqueous ones has significantly improved the homogeneity of the $\mathrm{Pd}-\mathrm{Au}$ phase of catalysts, i.e., narrower distributions of the size of metal nanoparticles and better homogeneity of bimetallic systems. Acetone, better than water, covers the hydrophobic surface of the carbon support and better penetrates its porous structure, which in effect leads to the preparation of catalysts with high dispersion of metallic phase and its homogeneity.

The XRD and TPHD methods were shown to be complementary when applied in probing the degree of $\mathrm{Pd}-\mathrm{Au}$ alloying in the tested catalysts. Cyclic voltammetry measurements contributed to determining the surface composition of synthesized $\mathrm{Pd}-\mathrm{Au}$ bimetallic particles with higher accuracy. Interestingly, the catalyst samples prepared with MW displayed increased content of $\mathrm{Pd}$ at the surface of nanoparticles.

The catalysts' activity was tested in the environmentally important process of hydrodechlorination of tetrachloromethane. Sibunit-supported Pd-Au catalysts displayed much better performance than the monometallic Pd species. Reaching the homogeneous $\mathrm{Pd}-\mathrm{Au}$ alloy phase in the catalysts was found to be a key to get catalysts of high efficacy. By using the catalyst prepared with MW irradiation and acetone as the solvent of metal precursor salts, we reported catalytic system with desirable properties: it assures lower amount of carbonaceous deposits and chlorine-containing species which retained on the catalyst during the $\mathrm{HdCl}$ of $\mathrm{CCl}_{4}$ and, consequently, a higher overall activity, better selectivity towards hydrocarbon products and higher deactivation resistance.

Author Contributions: M.B. synthesized the catalysts and performed catalytic tests. Z.K. collected and analyzed XRD patterns. K.M. collected and analyzed TEM micrographs. A.D. and T.S. carried out and analyzed cyclic voltammetry measurements. M.B. and A.K. performed data curation. M.B. wrote initial draft of the manuscript, with input from all the authors. A.K. coordinated funding acquisition as well as reviewing and editing the initial draft. All authors have read and agreed to the published version of the manuscript.

Funding: This research was supported from the statutory funds of the Institute of Physical Chemistry, Polish Academy of Sciences. The APC was funded by the Institute of Physical Chemistry, Polish Academy of Sciences.

Institutional Review Board Statement: Not applicable.

Informed Consent Statement: Not applicable.

Data Availability Statement: Raw data are available from the corresponding authors upon request.

Conflicts of Interest: The authors declare no conflict of interest.

\section{References}

1. Hu, L.; Montszka, S.A.; Miller, B.R.; Andrews, A.E.; Miller, J.B.; Lehman, S.J.; Sweeney, C.; Miller, S.M.; Thoning, K.; Siso, C.; et al. Continued emissions of carbon tetrachloride from the United States nearly two decades after its phaseout for dispersive uses. Proc. Natl. Acad. Sci. USA 2016, 113, 2880-2885. [CrossRef] 
2. Fluid, M.R.; Kartashov, L.M.; Treger Yu, A. Understanding Hydrodechlorination of Chloromethanes. Past and Future of the Technology. Catalysts 2020, 10, 1-52.

3. Fraser, P.J.; Dunse, B.L.; Manning, A.J.; Walsh, S.; Wang, R.H.J.; Krummel, P.B.; Steele, L.P.; Porter, L.W.; Allison, C.; O’Doherty, S.; et al. Australian carbon tetrachloride emissions in a global context. Environ. Chem. 2014, 11, 77-88. [CrossRef]

4. Odabasi, M.; Elbir, T.; Dumanoglu, Y.; Sofuoglu, S.C. Halogenated volatile organic compounds in chlorine-bleach-containing household products and implications for their use. Atmos. Environ. 2014, 92, 376-383. [CrossRef]

5. Bonarowska, M.; Kaszkur, Z.; Łomot, D.; Rawski, M.; Karpiński, Z. Effect of gold on catalytic behavior of palladium catalysts in hydrodechlorination of tetrachloromethane. Appl. Catal. B 2015, 162, 45-56. [CrossRef]

6. Tsai, W.-T. Fate of Chloromethanes in the Atmospheric Environment: Implications for Human Health, Ozone Formation and Depletion, and Global warming Impacts. Toxics 2017, 5, 23. [CrossRef] [PubMed]

7. Rafaïdeen, T.; Baranton, S.; Coutanceau, C. Pd-shaped nanoparticles modified by gold ad-atoms: Effects on surface structure and activity toward glucose electrooxidation. Appl. Catal. B Environ. 2019, 243, 641-656.

8. Tyagi, A.; Yamamoto, A.; Yoshida, H. Photocatalytic Ullmann coupling of aryl halides by a novel blended catalyst consisting of a $\mathrm{TiO}_{2}$ photocatalyst and an $\mathrm{Al}_{2} \mathrm{O}_{3}$ supported Pd-Au bimetallic catalyst. Catal. Sci. Technol. 2018, 8, 6196-6203. [CrossRef]

9. Yongli, S.; Kangjuan, Y.; Cuihua, A.; Zihui, X. Design of a difunctional Zn-Ti LDHs supported PdAu catalyst for selective hydrogenation of phenylacetylene. Appl. Surf. Sci. 2018, 456, 1-6.

10. Wu, Z.W.; Chiang, M.H.; Lee, C.L. Tuning saw-toothed morphology on $\mathrm{Pd} / \mathrm{Pt}$ nanocubes as oxygen reduction catalysts by co-surfactant synthesis method. Appl. Surf. Sci. 2018, 467, 844-850. [CrossRef]

11. Wilburna, M.S.; Epling, W.S. $\mathrm{SO}_{2}$ adsorption and desorption characteristics of bimetallic Pd-Pt catalysts: Pd:Pt ratio dependency. Catal. Today 2019, 320, 11-19. [CrossRef]

12. Mironenko, R.M.; Belskaya, O.B.; Lavrenov, A.V.; Likholobov, V.A. Palladium-Ruthenium Catalyst for Selective Hydrogenation of Furfural to Cyclopentanol. Kinet. Catal. 2018, 59, 339-346. [CrossRef]

13. Gloag, L.; Benedetti, T.M.; Cheong, S.; Marjo, C.E.; Gooding, J.J.; Tilley, R.D. Cubic-Core Hexagonal-Branch Mechanism To Synthesize Bimetallic Branched and Faceted Pd-Ru Nanoparticles for Oxygen Evolution Reaction Electrocatalysis. J. Am. Chem. Soc. 2018, 140, 12760-12764. [CrossRef] [PubMed]

14. Asset, T.; Serov, A.; Padilla, M.; Roy, A.J.; Matanovic, I.; Chatenet, M.; Maillard, F.; Atanassov, P. Design of Pd-Pb Catalysts for Glycerol and Ethylene Glycol Electrooxidation in Alkaline Medium. Electrocatalysis 2018, 9, 480-485. [CrossRef]

15. Coq, B.; Hub, S.; Figueras, F.; Tournigant, D. Conversion under hydrogen of dichlorodifluoromethane over bimetallic palladium catalysts. Appl. Catal. A Gen. 1993, 101, 41-50. [CrossRef]

16. Xu, H.; Yan, B.; Zhang, K.; Wang, J.; Li, S.M.; Wang, C.Q.; Du, Y.K.; Yang, P. Sub-5nm monodispersed PdCu nanosphere with enhanced catalytic activity towards ethylene glycol electrooxidation. Electrochim. Acta 2018, 261, 521-529. [CrossRef]

17. Jiang, X.; Jiao, Y.; Moran, C.; Nie, X.; Gong, Y.; Guo, X.; Walton, K.S.; Song, C. $\mathrm{CO}_{2}$ hydrogenation to methanol on PdCu bimetallic catalysts with lower metal loadings. Catalysis Comm. 2019, 118, 10-14. [CrossRef]

18. Coq, B.; Cognion, J.M.; Figuéras, F.; Tournigant, D. Conversion under hydrogen of dichlorodifluoromethane over supported palladium catalysts. J. Catal. 1993, 141, 21-33. [CrossRef]

19. Wiersma, A.; van de Sandt, E.J.A.X.; den Hollander, M.A.; van Bekkum, H.; Makkee, M.; Moulijn, J.A. Comparison of the Performance of Activated Carbon-Supported Noble Metal Catalysts in the Hydrogenolysis of $\mathrm{CCl}_{2} \mathrm{~F}_{2}$. J. Catal. 1998, 177, 29-45. [CrossRef]

20. Makkee, M.; Wiersma, A.; van de Sandt, E.J.A.X.; van Bekkum, H.; Moulijn, J.A. Development of a palladium on activated carbon for a conceptual process in the selective hydrogenolysis of $\mathrm{CCl}_{2} \mathrm{~F}_{2}$ (CFC-12) into $\mathrm{CH}_{2} \mathrm{~F}_{2}$ (HFC-32). Catal. Today 2000, 55, 125-137. [CrossRef]

21. Ramos, A.L.; Schmal, M.G.; Aranda, D.A.; Somorjai, G.A. Hydrodechlorination of dichlorodifluoromethane over palladium model catalysts and a comparison with the hydrodechlorination of 1,1-dichlorotetrafluoroethane. J. Catal. 2000, 192, 423-431. [CrossRef]

22. Karpiński, Z.; d'Itri, J.L. Hydrodechlorination of 1,1-Dichlorotetrafluoroethane on Supported Palladium Catalysts. A StaticCirculation Reactor Study. Catal. Lett. 2001, 77, 135-140.

23. Cao, Y.C.; Jiang, X.Z.; Song, W.H.; Bai, Z.Q.; Fang, X.Q. Hydrodechlorination of CFC-12 over Novel Supported Palladium Catalysts. Catal. Lett. 2001, 76, 53-57. [CrossRef]

24. Gao, F.; Goodman, D.W. Pd-Au bimetallic catalysts: Understanding alloy effects from planar models and (supported) nanoparticle. Chem. Soc. Rev. 2012, 41, 8009-8020. [CrossRef]

25. Nutt, M.O.; Hughes, J.B.; Wong, M.S. Designing Pd-on-Au bimetallic nanoparticle catalysts for trichloroethene hydrodechlorination. Environ. Sci. Technol. 2005, 39, 1346-1353. [CrossRef]

26. Pretzer, L.A.; Song, H.J.; Fang, Y.-L.; Zhao, Z.; Guo, N.; Wuc, T.; Arslan, I.; Miller, J.T.; Wong, M.S. Hydrodechlorination catalysis of Pd-on-Au nanoparticles varies with particle size. J. Catal. 2013, 298, 206-217. [CrossRef]

27. Bonarowska, M.; Pielaszek, J.; Semikolenov, V.A.; Karpiński, Z. Pd-Au/sibunit carbon catalysts: Characterization and catalytic activity in hydrodechlorination of dichlorodifluoromethane (CFC-12). J. Catal. 2002, 209, 528-538. [CrossRef]

28. Zhang, H.; Watanabe, T.; Okumura, M.; Haruta, M.; Toshima, N. Catalytically highly active top gold atom on palladium nanocluster. Nat. Mater. 2012, 11, 49-52. [CrossRef] [PubMed] 
29. Wang, A.Q.; Liu, X.Y.; Mou, C.Y.; Zhang, T. Understanding the synergistic effects of gold bimetallic catalysts. J. Catal. 2013, 308, 258-271. [CrossRef]

30. Chen, M.; Kumar, D.; Yi, C.W.; Goodman, D.W. The Promotional Effect of Gold in Catalysis by Palladium-Gold. Science 2005, 310, 291-293. [CrossRef]

31. Malinowski, A.; Juszczyk, W.; Pielaszek, J.; Bonarowska, M.; Wojciechowska, M.; Karpiński, Z. Magnesium fluoride as a catalytic support in hydrodechlorination of $\mathrm{CCl}_{2} \mathrm{~F}_{2}$ (CFC-12). Chem. Commun. 1999, 8, 685-686. [CrossRef]

32. Malinowski, A.; Juszczyk, W.; Pielaszek, J.; Bonarowska, M.; Wojciechowska, M.; Karpiński, Z. Hydrodechlorination of $\mathrm{CCl}_{2} \mathrm{~F}_{2}$ (CFC-12) by carbon- and $\mathrm{MgF}_{2}$-supported palladium and palladium-gold catalysts. Stud. Surf. Sci. Catal. 2000, 130, 1991-1996.

33. Bonarowska, M.; Rarog-Pilecka, W.; Karpiński, Z. The use of active carbon pretreated at $2173 \mathrm{~K}$ as a support for palladium catalysts for hydrodechlorination reactions. Catal. Today 2011, 169, 223-231. [CrossRef]

34. Palma, V.; Barba, D.; Cortese, M.; Martino, M.; Renda, S.; Meloni, E. Microwaves and Heterogeneous Catalysis: A Reviewon Selected Catalytic Processes. Catalysts 2020, 10, 246. [CrossRef]

35. Berry, F.J.; Smart, L.E.; Sai Prasad, P.S.; Lingaiah, N.; Kanta Rao, P. Microwave heating during catalyst preparation: Influence on the hydrodechlorination activity of alumina-supported palladium-iron bimetallic catalysts. Appl. Catal. A 2000, 204, 191-201. [CrossRef]

36. Rahsepar, M.; Kim, H. Microwave-assisted synthesis and characterization of bimetallic PtRu alloy nanoparticles supported on carbon nanotubes. J. Alloy. Compd. 2015, 649, 1323-1328. [CrossRef]

37. Bonarowska, M.; Matus, K.; Śrębowata, A.; Sá, J. Application of silica-supported Ir and Ir-M (M = Pt, Pd, Au) catalysts for low-temperature hydrodechlorination of tetrachloromethane. Sci. Total Environ. 2018, 644, 287-297. [CrossRef] [PubMed]

38. Galletti, A.R.M.; Antonetti, C.; Venezia, A.M.; Giambastiani, G. An easy microwave-assisted process for the synthesis of nanostructured palladium catalysts and their use in the selective hydrogenation of cinnamaldehyd. Appl. Catal. A 2010, 386, 124-131. [CrossRef]

39. Fenelonov, V.B.; Likholobov, V.A.; Derevyankin, A.Y.; Mel'gunov, M.S. Porous carbon materials prepared from C1-C3 hydrocarbons. Catal. Today 1998, 42, 341-345. [CrossRef]

40. Bonarowska, M.; Pielaszek, J.; Juszczyk, W.; Karpiński, Z. Characterization of Pd-Au/SiO 2 Catalysts by X-ray Diffraction, Temperature-Programmed Hydride Decomposition, and Catalytic Probes. J. Catal. 2000, 195, 304-315. [CrossRef]

41. Micheaud, C.; Guerin, M.; Marecot, P.; Geron, C.; Barbier, J. Preparation and characterization of Pd-Pt/ $\mathrm{Al}_{2} \mathrm{O}_{3}$ catalysts. J. Chim. Phys. 1996, 93, 1394-1411. [CrossRef]

42. Wojdyr, M. Fityk: A general-purpose peak fitting program. J. Appl. Cryst. 2010, 43, 1126-1128. [CrossRef]

43. Bonarowska, M.; Karpiński, Z. Application of the $\beta$-PdH decomposition for characterization of supported palladium catalysts. Pol. J. Chem. 2008, 82, 1973-1979.

44. Juszczyk, W.; Malinowski, A.; Karpiński, Z. Hydrodechlorination of $\mathrm{CCl}_{2} \mathrm{~F}_{2}$ (CFC-12) over $\gamma$-alumina supported palladium catalysts. Appl. Catal. A 1998, 166, 311-319. [CrossRef]

45. Ichikawa, S.; Poppa, H.; Boudart, M. Disproportionation of CO on small particles of silica-supported palladium. J. Catal. 1985, 91, 1-10. [CrossRef]

46. Krishnankutty, N.; Vannice, M.A. The Effect of Pretreatment on Pd/C Catalysts: I. Adsorption and Absorption Properties. J. Catal. 1995, 155, 312-326. [CrossRef]

47. Gurrath, M.; Kuretzky, T.; Boehm, H.P.; Okhlopkov, L.B.; Lisitsyn, A.S.; Likholobov, V.A. Palladium catalysts on activated carbon supports: Influence of reduction temperature, origin of the support and pretreatments of the carbon surface. Carbon 2000, 38, 1241-1255. [CrossRef]

48. Bonarowska, M.; Zieliński, M.; Matus, K.; Sá, J.; Śrębowata, A. Influence of microwave activation on the catalytic behavior of $\mathrm{Pd}-\mathrm{Au} / \mathrm{C}$ catalysts employed in the hydrodechlorination of tetrachloromethane. React. Kinet. Mech. Catal. 2018, 124, 375-388. [CrossRef]

49. Prati, L.; Martra, G. New gold catalysts for liquid phase oxidation. Gold Bull. 1999, 32, 96-101. [CrossRef]

50. Ma, Z.; Dai, S. Development of novel supported gold catalysts: A materials perspective. Nano Res. 2011, 4, 3-32. [CrossRef]

51. Williamson, G.K.; Hall, W.H. X-ray line broadening from filed aluminium and wolfram. Acta Metall. 1953, 1, 22-31. [CrossRef]

52. Tabakova, T.; Ilieva, L.; Ivanov, I.; Zanellab, R.; Sobczak, J.W.; Lisowski, W.; Kaszkur, Z.; Andreeva, D. Influence of the preparation method and dopants nature on the WGS activity of gold catalysts supported on doped by transition metals ceria. Appl. Catal. Environ. 2013, 136-137, 70-80. [CrossRef]

53. Cabello, G.; Davoglio, R.A.; Hartl, F.W.; Marco, J.F.; Pereira, E.C.; Biaggio, S.R.; Varela, H.; Cuesta, A. Microwave-Assisted Synthesis of Pt-Au Nanoparticles with Enhanced Electrocatalytic Activity for the Oxidation of Formic Acid. Electrochim Acta 2017, 224, 56-63. [CrossRef]

54. Boudart, M.; Hwang, H.S. Solubility of hydrogen in small particles of palladium. J. Catal. 1975, 39, 44-52. [CrossRef]

55. Newbatt, P.H.; Sermon, P.A.; Luengo, M.A.M. Rate of Hydrogen Sorption by Well-Dispersed Palladium. Z. Phys. Chem. 1986, 147, 105-114. [CrossRef]

56. Luo, S.; Wang, D.; Flanagan, T.B. Thermodynamics of Hydrogen in fcc Pd-Au Alloys. J. Phys. Chem. B 2010, 114, 6117-6125. [CrossRef] [PubMed]

57. Ziemecki, S.B.; Michel, J.B.; Jones, G.A. Hydride formation as a measure of alloying in bimetallic systems containing palladium. React. Solids 1986, 2, 187-202. [CrossRef] 
58. Szumełda, T.; Drelinkiewicz, A.; Lalik, E.; Kosydar, R.; Duraczyńska, D.; Gurgul, J. Carbon-supported Pd100-X AuX alloy nanoparticles for the electrocatalytic oxidation of formic acid: Influence of metal particles composition on activity enhancement. Appl. Catal. B Environ. 2018, 221,393-405. [CrossRef]

59. Szumełda, T.; Drelinkiewicz, A.; Kosydar, R.; Gurgul, J.; Duraczyńska, D.; Gurgul, J. Synthesis of carbon-supported bimetallic palladium-iridium catalysts by microemulsion; characterization and electrocatalytic properties. J. Mater. Sci. 2021, 56, 392-414. [CrossRef]

60. Lankiang, S.; Chiwata, M.; Baranton, S.; Uchida, H.; Coutanceau, C. Oxygen reduction reaction at binary and ternary nanocatalysts based on Pt, Pd and Au. Electrochim. Acta 2015, 182, 131-142. [CrossRef]

61. Łukaszewski, M.; Czerwiński, A. Selected electrochemical properties of Pd-Au alloys: Hydrogen absorption and surface oxidation. J. Solid State Electrochem. 2008, 12, 1589-1598.

62. Simoes, M.; Baranton, S.; Coutanceau, C. Electrooxidation of sodium Borohydride at Pd, Au and PdAu Carbon-Supported nanocatalysts. J. Phys. Chem. C 2009, 113, 13369-13376. [CrossRef]

63. Chen, J.; Wang, G.; Wang, X.; Tian, J.; Zhu, S.; Wang, R. Enhanced formic aid electro-oxidation on PdIr nanoparticles prepared by ethylene glycol-assisted NaBH4 reduction process. J. Nanosci. Nanotechnol. 2013, 13, 7008-7011. [CrossRef]

64. Łukaszewski, M.; Żurowski, A.; Grdeń, M.; Czerwiński, A. Correlations between hydrogen electrosorption properties and composition of Pd-noble metal alloys. Electrochem. Commun. 2007, 9, 671-676. [CrossRef]

65. Łukaszewski, M.; Kuśmierczyk, K.; Kotowski, J.; Siwek, H.; Czerwinski, A. Electrosorption of hydrogen into palladium-gold alloys. J. Solid State Electrochem. 2003, 7, 69-76. [CrossRef]

66. Hu, S.; Ha, S.; Scudiero, L. Temperature dependence study of Pd-Cu supported bimetallic films by photoelectron spectroscopy and cyclic voltammetry. Electrochim. Acta 2013, 105, 362-370. [CrossRef]

67. Rand, D.A.I.; Woods, R. Determination of the surface composition of smooth noble metal alloys by cyclic voltammetry. J. Electroanal. Chem. 1972, 36, 57-69. [CrossRef]

68. Keane, M.A.; Gómez-Quero, S.; Cárdenas-Lizana, F.; Shen, W.Q. Alumina-supported Ni-Au: Surface synergistic effects in catalytic hydrodechlorination. ChemCatChem 2009, 1, 270-278. [CrossRef]

69. Dal Santo, V.; Dossi, C.; Recchia, S.; Colavita, P.E.; Vlaic, G.; Psaro, R. Carbon tetrachloride hydrodechlorination with organometallics-based platinum and palladium catalysts on MgO. J. Mol. Catal. A Chem. 2002, 182-183, 157-166. [CrossRef]

70. Golubina, E.V.; Lokteva, E.S.; Lunin, V.V.; Turakulova, A.O.; Simagina, V.I.; Stoyanova, I.V. Modification of the supported palladium catalysts surface during hydrodechlorination of carbon tetrachloride. Appl. Catal. A Gen. 2003, 241, 123-132. [CrossRef]

71. Öcal, M.; Maciejewski, M.; Baiker, A. Conversion of $\mathrm{CCl}_{2} \mathrm{~F}_{2}$ (CFC-12) in the presence and absence of $\mathrm{H}_{2}$ on sol-gel derived $\mathrm{Pd} / \mathrm{Al}_{2} \mathrm{O}_{3}$ catalysts. Appl. Catal. B 1999, 21, 279-289. [CrossRef]

72. Morato, A.; Alonso, C.; Medina, F.; Garreta, J.L.; Sueiras, J.E.; Cesteras, Y.; Salagre, P.; Tichit, D.; Coq, B. KMg $1-x \mathrm{xdxF}_{3}$ with Perovskite-Like Structures as Precursors for the Catalytic Hydroconversion of $\mathrm{CCl}_{2} \mathrm{~F}_{2}$ and $\mathrm{CHClF}_{2}$. Catal. Lett. 2001, 77, 141-146. [CrossRef]

73. Bonarowska, M.; Malinowski, A.; Juszczyk, W.; Karpiński, Z.; Karpiński, Z. Hydrodechlorination of $\mathrm{CCl}_{2} \mathrm{~F}_{2}(\mathrm{CFC}-12)$ over silica-supported palladium-gold catalysts. Appl. Catal. B 2001, 30, 187-193. [CrossRef]

74. Stachurski, J.; Frąckiewicz, A. A new phase in the Pd-C system formed during the catalytic hydrogenation of acetylene. J. Less-Common Met. 1985, 108, 249-256. [CrossRef]

75. Ziemecki, S.B.; Jones, G.A.; Swartzfager, D.G.; Harlow, R.L.; Faber, J. Formation of interstitial palladium-carbon phase by interaction of ethylene, acetylene, and carbon monoxide with palladium. J. Am. Chem. Soc. 1985, 107, 4547-4548. [CrossRef]

76. Kaszkur, Z.; Stachurski, J.; Pielaszek, J. X-ray diffraction study of the palladium-carbon system. J. Phys. Chem. Solids 1986, 47, 795-798. [CrossRef]

77. Barin, I. Thermochemical Data of Pure Substances, 3rd ed.; VCH: Weinheim, Germany, 1995.

78. Chen, R.N.; Rioux, M.M.; Barbosa, L.A.M.; Ribeiro, F.H. Kinetic and Theoretical Study of the Hydrodechlorination of $\mathrm{CH}_{4-\mathrm{x}} \mathrm{Cl}_{\mathrm{x}}$ (x = 1-4) Compounds on Palladium. Langmuir 2010, 26, 16615-16624. [CrossRef] [PubMed] 